|20025855.FSTII_._RI.090403

FULLERENES, NANOTUBES, AND CARBON NANOSTRUCTURES

Vol. 11, No. 4, pp. 333-370, 2003

\title{
Terrestrial and Extraterrestrial Fullerenes
}

\author{
D. Heymann, ${ }^{1,}{ }^{*}$ L. W. Jenneskens, ${ }^{2}$ J. Jehlička, ${ }^{3}$ C. Koper, ${ }^{2}$ \\ and E. Vlietstra ${ }^{2}$ \\ ${ }^{1}$ Department of Earth Science, Rice University, Houston, Texas, USA \\ ${ }^{2}$ Debye Institute, Department of Physical Organic Chemistry, \\ Utrecht University, Utrecht, The Netherlands \\ ${ }^{3}$ Institute of Geochemistry, Charles University, Prague, \\ Czech Republic
}

\begin{abstract}
This paper reviews reports of occurrences of fullerenes in circumstellar media, interstellar media, meteorites, interplanetary dust particles (IDPs), lunar rocks, hard terrestrial rocks from Shunga (Russia), Sudbury (Canada) and Mitov (Czech Republic), coal, terrestrial sediments from the Cretaceous-Tertiary-Boundary and Permian-Triassic-Boundary, fulgurite, ink sticks, dinosaur eggs, and a tree char. The occurrences are discussed in the context of known and postulated processes of fullerene formation, including the suggestion that some natural fullerenes might have formed from biological (algal) remains.

Key Words: Fullerenes; Stellar media; Moon; Meteorites; Terrestrial rocks; Biogenic formation.
\end{abstract}

*Correspondence: Dieter Heymann, Department of Earth Science, Rice University, Houston, TX 77251-1892, USA; E-mail: dieter@rice.edu.

DOI: $10.1081 /$ FST-120025855

Copyright (C) 2003 by Marcel Dekker, Inc.
1536-383X (Print); 1536-4046 (Online) www.dekker.com 


\section{INTRODUCTION}

When Kroto et al. ${ }^{[1]}$ discovered buckminsterfullerene, they predicted that this surprisingly stable carbon molecule should occur abundantly in circumstellar and interstellar media, hence in meteorites. Astronomers almost immediately began searches for fullerenes and fullerene derivatives in interstellar and circumstellar media. When Krätschmer et al. ${ }^{[2]}$ first synthesized macroscopic amounts of $\mathrm{C}_{60}$ and discovered that the fullerenes were soluble in organic solvents such as toluene and in $\mathrm{CS}_{2}$, the search for fullerenes in terrestrial and extraterrestrial rocks became possible and began. All searches had in common not only the excitement of the hunt, but, if fullerenes were found, speculations on how and where these had formed in the first place. There ensued therefore an interesting interaction between geoand cosmochemists on the one hand and fullerene chemists on the other (see Ref. $^{[3]}$ ). In this review we will report the story of the successes and failures of searches for fullerenes in nature and the interpretations of their formation or absence.

The reader of publications on terrestrial and extraterrestrial fullerenes will be confronted with apparently conflicting results. For example, one group of investigators reported the finding of fullerenes in samples of the Allende meteorite $^{[4]}$ while others have failed to find fullerenes in other samples of the same meteorite. ${ }^{[5-10]}$ We will never use the statement "there are no fullerenes in the Allende meteorite" but we shall assume that "group A found fullerenes in their samples of Allende" or "group B found no fullerenes in their samples of Allende". Even when there were doubts expressed about a discovery of fullerenes "in the wild" we will treat every discovery as real unless retracted by its authors.

We have attempted to find and include most relevant publications up to December 31, 2002, including significant conference abstracts. Occasionally such abstracts are the only reports available on a specific topic. The great majority of abstracts cited are from the annual Lunar and Planetary Science Conferences or the annual Meetings of the Meteoritical Society. The former can be ordered from the Lunar and Planetary Institute, Houston, TX, USA; the latter are printed in the regular issues or supplements of Meteoritics (now Meteoritics and Planetary Science) An exception to completeness was made for publications in the fields of fullerene photo- and pressure-polymerization, fullerene synthesis by carbon condensation, and fullerene synthesis by oxygen-starved combustion of organic compounds. The number of papers in each of these fields is so large that we decided to cull for citation only a few papers from each of these. The reference section of this paper lists a large number of entries. This is deliberately done to ease literature researches of future investigators of fullerenes in nature. 


\section{FULLERENE ASTROCHEMISTRY}

Analysis of all manifestations of electromagnetic radiation is the only diagnostic tool that astronomers have to survey for electrons, ions, atoms, molecules, macromolecules and solid grains ("stardust") in the Universe. Every conclusion that one of these is discovered must be confirmed by analogous experimental or theoretical studies in the laboratory. Given the huge number of known atoms, molecules, and minerals, inorganic as well as organic, that seems to be a relatively simple task, but it can also be frustrating when more than one molecule or cluster of molecules emits, absorbs, polarizes, or scatters light at or very near the wavelengths of interest.

When fullerenes were discovered there already existed a number of enigmatic observations concerning radiation received from interstellar media. Foremost among these were the general shape of the interstellar extinction curve for the Galaxy with its strong, but broad feature centered at $217 \mathrm{~nm}$, and the socalled diffuse interstellar bands (DIBs), which are spectral features arising from absorption of light by matter in the diffuse interstellar gas. The strong $217 \mathrm{~nm}$ absorption band was variously attributed to graphite, carbonaceous materials, carbon compounds processed on icy grains, or carbon onions, but there are problems with all of these (see for example Ref. ${ }^{[11]}$ ). Thirty-nine DIBs were known in 1975 and about 80 in 1988. Today they number more than 200. Diffuse interstellar bands range in frequency from the visible to the infrared. A variety of carbon-bearing compounds was proposed as carriers, but the most widely touted of these were ionized PAHs. ${ }^{[12-15]}$ The initial problem with PAHs was an "embarrassment of riches" because it was concluded that the already known PAHs should give rise to many more DIBs than observed, unless one accepted that only a restricted number of PAHs actually occurred in interstellar media.

Onto this smorgasbord of astrochemical compounds fell the fullerenes and they, as well as some of their derivatives, immediately became potential candidates for the interstellar extinction curve, its $217 \mathrm{~nm}$ maximum, and the DIBs. A major observational problem, until after 1990, when macroscopic amounts of $\mathrm{C}_{60}$ became available, was that only one absorption feature of $\mathrm{C}_{60}$ at $386.0 \mathrm{~nm}$ had been determined. ${ }^{[16]}$ All other assignments of fullerenes to specific DIBs had to be checked by theoretical calculations of the unknown energies of electronic and vibrational transitions of fullerenes and fullerene derivatives. Today, the results of searches for fullerenes in interstellar media have achieved very modest, but still much debated results. Perhaps the strongest evidence was the fit of a few DIBs in the infrared with measured absorption bands of $\mathrm{C}_{60}{ }^{+[17-24]}$ and of the interstellar extinction curve with its $217 \mathrm{~nm}$ maximum with $\mathrm{C}_{60}$ and fulleranes, the hydrogenated fullerenes $\mathrm{C}_{60} \mathrm{H}_{2 n}(n=1-30) .{ }^{[25-30]}$ However, even in these cases there remained strong reservations about the assignments. ${ }^{[31,32]}$ There were also failures to associate specific DIBs with 
known electronic and vibrational transitions of fullerenes and fullerene derivatives, especially in the $U V^{[33-35]}$ A study of light emitted from a proto-planetary nebula concluded that the observed electromagnetic features could be best explained by a mixed population of hydrogenated amorphous carbonaceous grains, fullerenes with different degrees of hydrogenation, partially dehydrogenated cationic PAH molecules, and crystalline silicates, ${ }^{[36,37]}$ quite an assortment of compounds. Nevertheless, that is perhaps much more realistic than claims that any specific, single carbon compound is greatly dominant in such environments.

If fullerenes occur in interstellar media, how were they formed and from where did they come? The most widely held view is that interstellar fullerenes formed initially in atmospheres of carbon-rich, hydrogen-poor stars whence they are delivered by strong stellar winds to interstellar media. Possible syntheses include carbon condensation, ${ }^{[1,38-42]}$ but also hydrogenation, ${ }^{[25-30]}$ pyrolysis of gaseous molecules, ${ }^{[43]}$ and decomposition of hydrogenated amorphous carbon. ${ }^{[4]}$ Unfortunately, extensive experimental evidence shows that many other forms of elemental carbon are likely to form alongside fullerenes and it is still not understood which of these will be the most abundant in any of the relevant astrochemical environments. Today, most investigators of formation of fullerenes in stellar atmospheres consider the simultaneous formation of amorphous carbon, carbon onions, carbon black, and carbynes in variable proportions.

Once delivered to interstellar media, the fullerenes and fullerene derivatives participate in the complex chemistry of these environments. Detailed experimental and theoretical studies on this subject have been published. ${ }^{[45-49]}$ The following is a summary of the pertinent observations and conclusions. The high ionization energy of $\mathrm{C}_{60}$ and the low UV flux in interstellar clouds essentially preclude direct photoionization, but charge transfer electron detachment from $\mathrm{He}^{+}$or interactions with cosmic ray protons may produce $\mathrm{C}_{60}{ }^{2+}$ and $\mathrm{C}_{60}{ }^{3+}$. The most likely loss process for both species is partial neutralization with electrons, eventually to $\mathrm{C}_{60}{ }^{+}$. Whether $\mathrm{C}_{60}{ }^{-}$ions can form either by free electron attachment or by electron transfer with negatively charged PAHs is not clear. Once formed, however, $\mathrm{C}_{60}{ }^{-}$ions should be quite stable given the high electron affinity of the neutral molecule. The three positive ions can react, however, with various molecules in interstellar clouds. Their reactivity decreases from $\mathrm{C}_{60}{ }^{3+}$ to $\mathrm{C}_{60}{ }^{+}$. The reactants studied include $\mathrm{C}_{6} \mathrm{H}_{6}, \mathrm{C}_{20} \mathrm{H}_{10}, \mathrm{C}_{14} \mathrm{H}_{10}, \mathrm{CH}_{3} \mathrm{OH}, \mathrm{HC}_{3} \mathrm{~N}, \mathrm{NH}_{3}$, and many others. With acenes, the ions, like neutral $\mathrm{C}_{60}$, form [4+2] cycloadducts. Adduction with condensed PAHs such as corannulene, results in a charge-transfer complex. These papers do not present any calculated equilibrium distribution of the various fullerenic molecules because that cannot be done reliably until the reaction of $\mathrm{C}_{60}$ with atomic hydrogen becomes better studied. They suggest, however, that neutral $\mathrm{C}_{60}$ is likely to be the most abundant fullerenic molecule in interstellar media, if such molecules exist there at all. 
In summary, while there are tantalizing hints, there is no solid evidence that fullerene molecules, ions, or their derivatives actually occur in circumstellar and interstellar media. The notion that interstellar media are, hence the solar nebula was rich in fullerenes, available there in abundance to be picked up by meteorites or their precursor materials is unwarranted.

\section{FULLERENES IN ROCKS}

\subsection{Meteorites and Interplanetary Dust Particles}

Soon after fullerenes were discovered it was suggested that they might occur in meteorites as a kind of "molecular bottles" for certain isotopically anomalous trapped noble gases. ${ }^{[50]}$ However, it was subsequently found that these gases were actually contained in nanodiamonds. ${ }^{[51]}$ Nevertheless, precisely because the nanodiamonds and the later discovered graphite and silicon carbide grains in meteorites are interstellar, it seemed logical to search for possibly interstellar fullerenes in meteorites also.

There are three major classes of meteorites: the iron-, stony- and stonyiron meteorites. Elemental carbon occurs in meteorites of all three, but the thermal and metallurgical histories of the iron meteorites, whose metals were once molten and many of which contain graphite, mitigates against them containing fullerenes, and no searches for fullerenes were ever made in iron or stony-iron meteorites. Among the stony meteorites it is the carbonaceous chondrites that are the richest in presolar grains, hence are the most likely extraterrestrial rocks to contain presolar fullerenes.

The search for fullerenes in rocks is a comparatively simple geochemical procedure. $\mathrm{CS}_{2}$ and aromatic organic solvents were used for the extraction of fullerenes from rocks when it became understood that $\mathrm{C}_{60}$ and $\mathrm{C}_{70}$ dissolve well in them. Most analytical procedures begin therefore with solvent-extraction of either the powdered meteorite or its so-called "acid-resistant residues" (ARRs), carbonenriched residues obtained by the dissolution of inorganic minerals usually with $\mathrm{HF}-\mathrm{HCl}$. One assumes that the fullerenes are not too strongly locked up in the powdered meteorites or ARRs and that the chemical treatments do not destroy them. Studies of the geochemical behavior of fullerenes have shown that the HF$\mathrm{HCl}$ treatments do not degrade them but very strongly oxidizing chemicals such as hot perchloric acid do ${ }^{[52]}$ Meteorite extracts were always in contact with air at some stage of the analysis but in darkness and even in conditions of moderate light (e.g. lab benches) molecular oxygen does not react detectably with fullerenes. However, ozone swiftly oxidizes fullerenes in solution. ${ }^{[53]}$

After filtration the extracts are analyzed by HPLC or by mass spectrometry (or, as in a few studies, by both). HPLC has the advantage that fullerenes are 
neither formed nor destroyed by this technique and that rather precisely calibrated quantitative data can be obtained. A potential problem is that fullerenes and several organic compounds with closely similar retention times and UV-VIS absorption spectra could be present in the extracts. This problem can be alleviated but not completely removed by the use of different HPLC columns for the analysis of the same sample. ${ }^{[10]}$ mass spectroscopy, the characteristic set of isotopic peaks at $m / z=720-724 \mathrm{amu}$ in spectra is used for proving the presence of $\mathrm{C}_{60}$ in the sample, but when laser desorption-ionization is used there is the potential risk that fullerene ions are actually formed in the process from carbonaceous matter or hydrocarbons. Also, mass spectrometric methods have not yet yielded precise quantitative data. In one study, the extraction of fullerenes was attempted by sublimation in the range $300-600^{\circ} \mathrm{C}$, followed by mass spectrometric analysis. ${ }^{[7]}$ Two papers reported negative results of searches for fullerenes in two meteorites by vacuum pyrolysis. ${ }^{[5,6]}$

Table 1 presents a summary of the results of all searches for fullerenes in meteorites. Dr. P. Buseck (personal communication of unpublished results) did

Table 1. Reported fullerene contents in meteorites.

\begin{tabular}{|c|c|c|c|c|}
\hline Meteorite & $\mathrm{C}_{60}(\mathrm{ppm})$ & $\mathrm{C}_{70}(\mathrm{ppm})$ & Higher $^{\mathrm{a}}$ & Reference \\
\hline Allende $^{\mathrm{b}}$ & 100 & & & {$[4]$} \\
\hline Allende & detected & detected & detected & [54] \\
\hline Allende $^{c}$ & all <1 & & & {$[150,151,157$} \\
\hline Allende & detected & detected & & {$[55]$} \\
\hline Allende & detected & detected & detected & [54] \\
\hline Allende & 10 & & & [56] \\
\hline Allende & 10 & & & {$[56]$} \\
\hline Allende & 5 & & & {$[56]$} \\
\hline Allende ${ }^{\mathrm{d}}$ & all $<3$ & & & [56] \\
\hline Allende & detected & detected & detected & {$[57,58]$} \\
\hline Murchison & not detect. & & & {$[5,6]$} \\
\hline Murchison & $<2$ & & & {$[7]$} \\
\hline Murchison & not detect. & & & [157] \\
\hline Murray & not detect. & & & {$[5,6]$} \\
\hline
\end{tabular}

${ }^{a}$ Higher means $C>70$

${ }^{\mathrm{b}}$ Arranged in order of year of publication

${ }^{\mathrm{c}} \mathrm{A}$ total of nine distinct samples

${ }^{\mathrm{d}} \mathrm{A}$ total of seven distinct samples. 
differences. Chondritic meteorites are known to be mineralogically heterogeneous clastic breccias, hence the analysis of one large and homogenized sample, or of a number of smaller samples may be required to find any fullerenes present in a given meteorite. Some of the negative results could be due to inefficient fullerene extraction.

It appears then that fullerenes occur heterogeneously distributed in ppb quantities in the Allende meteorite. It has not been convincingly demonstrated that they occur in other meteorites. Again the questions are: how and where did the Allende fullerenes form? It was suggested that these had formed around C-rich stars, had made it into interstellar media and eventually via the solar nebula into the meteorites, ${ }^{[4]}$ but it was also suggested that the formation of fullerenes and fulleranes could have occurred in the solar nebula. ${ }^{[55,56]}$ The most recent studies report the occurrence of noble gas atoms trapped in Allende fullerene molecules. ${ }^{[57,58]}$ The composition of the trapped gas is that of the wellknown meteoritic component of "planetary noble gases", which were suggested to have been trapped in a carbonaceous meteoritic phase in the cooling solar nebula. ${ }^{[59]}$ Some, or even all of the fullerene molecules of Allende may therefore have formed in the solar system but it is still unclear how and where. We suggest here that clues may be found in the nature of the carbonaceous matter of the Allende meteorite. In most carbonaceous meteorites, the bulk of the element carbon occurs as a complex organic polymer. Allende is exceptional because the element is a poorly ordered carbon, characterized from studies by transmission electron microscopy as "glassy carbon". ${ }^{[60,61]}$ A more recent TEM study of Allende carbon supports this finding and reports the abundant occurrence of "carbon black-like particles" Vis et al. ${ }^{[62]}$ Taken together these observations suggest that Allende carbon formed by pyrolysis of hydrocarbons and polymeric hydrocarbons, in part in a gas phase, in part perhaps on hot mineral surfaces. Such a scenario for the formation of fullerenes is not too outlandish when one considers that fullerenes have been synthesized by the pyrolysis of naphtalene ${ }^{[63]}$ and by the consecutive/multiple cyclodehydrogenation of even more complex trimerized PAHs. ${ }^{[64-69]}$

It has been suggested that pre-terrestrial fullerenes are an important carrier phase for the noble gases of the atmospheres of the terrestrial planets. ${ }^{[57,58]}$ That is questionable because it can be shown that the Allende ARR must contain more than $1 \mathrm{~g} \mathrm{C}_{60}$ per gram to account for all so-called planetary $\mathrm{He}$ and that is obviously impossible.

Interplanetary dust particles (IDPs) constitute a circumsolar dust system. It is generally assumed that this system must be continuously refreshed with particles from comets and asteroid collisions. The particles have been collected in the Earth's stratosphere and by Earth-orbiting spacecraft but also from the mid-oceanic seafloor and polar ice deposits. Interplanetary Dust Particles range in size from about one micrometer to about $1 \mathrm{~mm}$. It is not 
clear why IDPs might contain fullerenes unless one argues that the collisions of and impacts on chondrite parent bodies in the asteroid belt releases fullerene-bearing chondrite dust. Bajt and his coworkers searched for fullerenes in IDPs. ${ }^{[70,71]}$ The result, although seemingly encouraging, was nevertheless inconclusive. More recently, Becker and Poreda ${ }^{[72]}$ have suggested that IDPs contain noble gas-laden fullerenes.

\subsection{Fullerenes were not found on the Moon}

The discovery of fullerenes on the skin of the Long Duration Exposure Facility (LDEF) spacecraft in Earth orbit, possibly formed by a high-energy impact from carbon of a micrometeorite, ${ }^{[73]}$ suggested that fullerenes might occur in the lunar regolith, the fragmented and unconsolidated outermost rocky layer of the Moon. Impact craters with a large range of diameters are abundant selenographic surface features and some of the impactors are likely to have contained elemental carbon or carbon compounds from which fullerenes could have formed in some of these violent events. A search for fullerenes in samples returned by Apollo missions was therefore undertaken. ${ }^{[74]}$ Two samples of so-called "lunar fines", i.e. $<1 \mathrm{~mm}$ particles from the regolith, were made available by NASA. One was $5.006 \mathrm{~g}$ of fines collected directly at the surface of the Apollo 11 landing site. The other was a 7-17 cm depth subsurface sample of $0.972 \mathrm{~g}$ fines collected in the Van Serg trench at the Apollo 17 site. The samples were extracted with toluene and were analyzed by HPLC. No fullerenes were detected at the $1 \mathrm{ppb}$ level or higher.

These negative results must be evaluated in the context of the puny fraction of lunar regolith matter that was actually studied. The regolith content of fullerenes could be grossly heterogeneous with detectable amounts present at young craters but none in older terranes as there are several processes that could dilute or even destroy regolith fullerenes in the course of time. Elemental carbon, including fullerenes, can react with impact-molten silicates to form $\mathrm{CO}$ and $\mathrm{CO}_{2}$ that escape from the Moon, one explanation for the surprisingly small carbon contents of lunar fines and rocks. ${ }^{[75-78]}$ Also, fullerenes can become destroyed on the Moon by thermal decomposition, ${ }^{[79-81]}$ destruction by electrons and ions from the solar wind and cosmic rays ${ }^{[82-86]}$ and become photo- or pressure-polymerized $^{[87,88]}$ in the harsh environment of the lunar regolith. Fullerene multimers, because of their very low solubilities in organic solvents, are very hard to detect. An additional loss mechanism from the equatorial region of the Moon is due to the estimated relatively short sticking time of $270 \mathrm{~s}$ of $\mathrm{C}_{60}$ at the very top of the regolith of the two landing sites. That time rapidly lengthens towards the cooler lunar Poles, which means that fullerenes could have slowly migrated north- and southward away from the more equatorial 
Apollo sampling areas. ${ }^{[89]}$ The diffusional migration can also proceed downward into the regolith because the penetration of the diurnal lunar heat wave is very shallow. That was the reason why the Apollo 17 sample was studied.

\subsection{Terrestrial Rocks, Overview}

Fullerenes have been reported in two distinctly different kinds of terrestrial rocks: hard, carbon-rich formations and sediments. The hard materials occur in the so-called shungite formation of Karelia, Russia, in the large-body impact structure at Sudbury, Ontario, Canada, and in bitumens among pillow-lavas of the Bohemian massif, Czech Republic, and Coals of the Yunnan province of the People's Republic of China. These materials may have in common that their parent materials were biological remains. The sedimentary rocks come from formations at the Creataceous-Tertiary Boundary (KTB) and the PermoTriassic Boundary (PTB). These formations are associated with catastrophic mass extinctions of species. Figure 1a shows the locations of fullerenes in hard rocks. Figure $1 \mathrm{~b}$ shows the locations of fullerenes in sedimentary rocks.

\subsection{Hard Rocks}

\subsubsection{Shungite}

We received valuable guidance and information for the writing of this section from an unpublished manuscript by Dr. Buseck. Buseck et al. ${ }^{[0]}$ reported the serendipitous finding of $\mathrm{C}_{60}$ by high-resolution transmission electron microscopy in shungite, a metamorphosed carbon-rich rock within Precambrian sediments of about $1.8 \mathrm{~Gy}$ on the Kola Peninsula of Russia. They followed through by analyzing powdered samples with Laser Desorption Mass Spectrometry (LDMS), which confirmed the presence of the fullerene. ${ }^{[11,92]} \mathrm{A}$ number of subsequent studies have also found small concentrations of $\mathrm{C}_{60}$ in shungite. ${ }^{[93-101]}$ Other investigators have questioned these reports or have failed to find fullerenes in their samples of shungite. ${ }^{[102,103]}$

The presence of $\mathrm{C}_{60}$ in shungite is enigmatic. There is no evidence for any high-energy events at Shunga such as a meteorite impact structure or lightning strikes. ${ }^{[104,105]}$ Because the age of the Karelian shungite could be closely the same as that of the Sudbury impact structure (see below) it seems marginally possible that the shungite $\mathrm{C}_{60}$ is due to a world-wide fullerene-bearing dust deposit from the Sudbury event. If, however, the formation was local or in situ, then one must try to understand the origin of the $\mathrm{C}_{60}$ in the context of the origin and formation of the carbon itself. The principal sources for the shungite can be either biogenic or volcanogenic. ${ }^{[106]}$ It is not yet known 

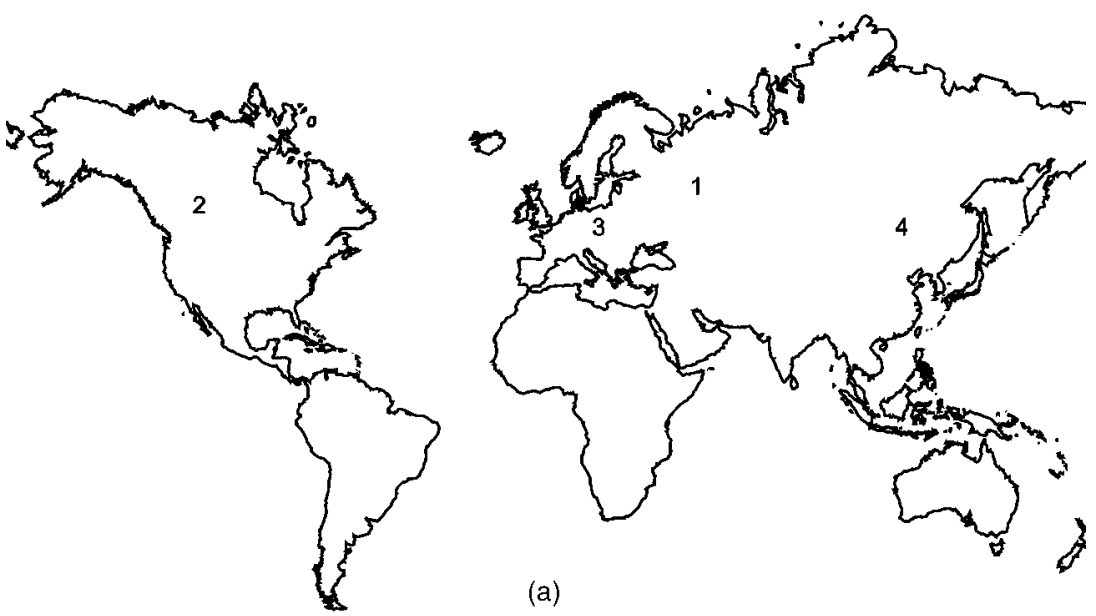

(a)
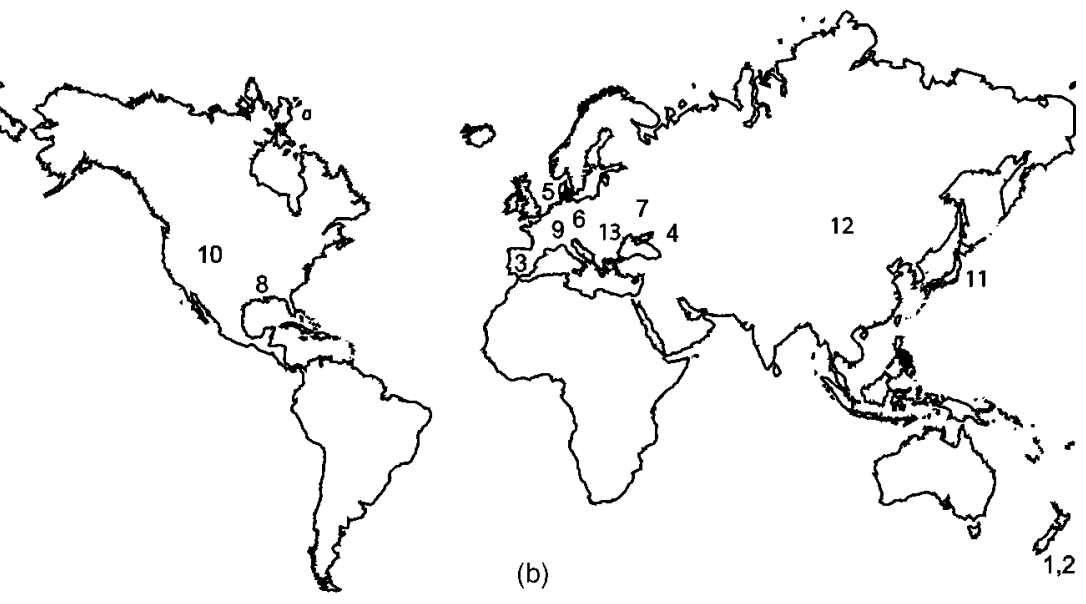

Figure 1. (a) World map showing the locations where fullerenes were reportedly found in hard rocks. 1=Shunga, Karelia, Russia. 2=Sudbury, Ontario, Canada. 3= Mitov, Czech Republic. 4=Yunnan Province, Peoples Republic of China. (b) World map showing the locations where fullerenes were searched in soft rocks. $1=$ Woodside Creek, New Zealand. 2 = Flaxbourne River, New Zealand. 3 = Caravaca, Spain. 4=Sumbar, Turkmenistan. 5=Stevns Klint, Denmark. 6=Elendgraben, Austria. $7=$ Tetri Tskaro, Georgia. 8= Brazos River, Texas, USA. $9=$ Gubbio, Italy. $10=$ Raton Basin (Boca Raton), Colorado, USA; $11=$ Sasayama, Japan. $12=$ Meishan, Peoples Republic of China. 13 = Bálvány, Hungary. 
whether fullerenes occur in volcanic exhalations. If the $\mathrm{C}_{60}$ is a metamorphic product of local biogenic matter, in this case most likely remains of blue-green algae, then one must try to understand its formation in the context of the graphitization of such remains.

A Science Magazine article that accompanied the discovery paper ${ }^{[107]}$ cites the opinion of several experts that fullerenes cannot form in condensed phases. That may, or may be not so, but the precursor materials of shungite and the later to be discussed bitumens of the Bohemian Massif had probably significant internal gas phases in which fullerenes could have formed at sufficiently high temperatures. Shungite carbon has been characterized as "glassy". $[90,106,108-110]$ Glassy carbon is a pyrocarbon with internal voids that typically forms by the pyrolysis of polymerized hydrocarbons on hot surfaces. ${ }^{[111,112]}$ Other investigators report "carbon black particles" ${ }^{, 113]}$ and "multilayered hollow globules" ${ }^{[114]}$ in shungite. The globules are probably not fullerene-like structures but graphitized carbon black. $\mathrm{C}_{60}$ could also have formed during the transformation of algal remains to glassy carbon if a biogenic $\mathrm{C}_{60}$ precursor was present early on. PAHs in general have frequently been suggested as potential $\mathrm{C}_{60}$ precursors, but very recently it has been shown specifically that the $\mathrm{C}_{20} \mathrm{H}_{12}$ PAH 4,5-dihydrobenz[1]acephenanthrylene with molten $\mathrm{S}_{8}$ readily cyclotrimerizes to two possible $\mathrm{C}_{60} \mathrm{H}_{30}$ isomers of which one, viz. benzo[1,2-e:3,4-e':5,6-e $\left.\mathrm{e}^{\prime \prime}\right]$ tribenzo[1] acephenanthrylene $\left(\mathrm{C}_{3}\right.$ symmetry), possesses the exact carbon atom topology of the $\mathrm{C}_{60}$ Schlegel diagram. ${ }^{[64,65]}$ Unfortunately, however, under the $\mathrm{S}_{8}$-mediated cyclotrimerization conditions the wrong $\mathrm{C}_{60} \mathrm{H}_{30}$ isomer, viz. benzo[1,2-e:3,4-e':6,5-e $\left.\mathrm{e}^{\prime \prime}\right]$ tribenzo[1]acephenanthrylene, which possesses $\mathrm{C}_{1}$ symmetry and thus a carbon atom topology that does not match the $\mathrm{C}_{60}$ Schlegel diagram is the prevalent product (Fig. 2). Hence, upon cyclodehydogenation, i.e. constructive $\mathrm{H}_{2}$ losses and ring closures, of the $\mathrm{S}_{8}$ cyclotrimerization reaction mixture under MALDI TOF-MS (positive ion mode) conditions only the curved PAH $\mathrm{C}_{60} \mathrm{H}_{10}$ and $\mathrm{C}_{60} \mathrm{H}_{12}$ were obtained. No evidence for the formation of $\mathrm{C}_{60}$ was found. ${ }^{[64]}$ Fortunately, an independent regio-chemically controlled synthesis of the proper $\mathrm{C}_{60} \mathrm{H}_{30}$ cyclotrimer became available ${ }^{[115]}$ and it was recently shown that under similar MALDI TOF-MS (positive ion mode) conditions this $\mathrm{C}_{60} \mathrm{H}_{30}$ isomer fully dehydrogenates to $\mathrm{C}_{60} \cdot{ }^{[64-67,69]}$ The viability of the stepwise zipping up of the proper $\mathrm{C}_{60} \mathrm{H}_{30} \mathrm{PAH}\left(\mathrm{C}_{3}\right.$ symmetry) to $\mathrm{C}_{60}$ is supported by semiempirical (AM1, PM3) as well as ab initio calculations (Fig. 3). ${ }^{[67,69]}$ It is interesting to note that $\mathrm{C}_{70}$ cannot form by a related cyclotrimerization/dehydrogenation process of single $\mathrm{PAH}$ precursors because suitable precursors do not exist $(70: 3=23.33 !) \cdot{ }^{[68,116]}$ Exactly which conditions the shungite formation has experienced is still unresolved. If that was greenschist facies metamorphism, then any algal remains were exposed to temperatures in the range $300-500^{\circ} \mathrm{C}$ for several $10^{5}$, perhaps $10^{6}$ years. 


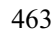

464

465

466

467

468

469

470

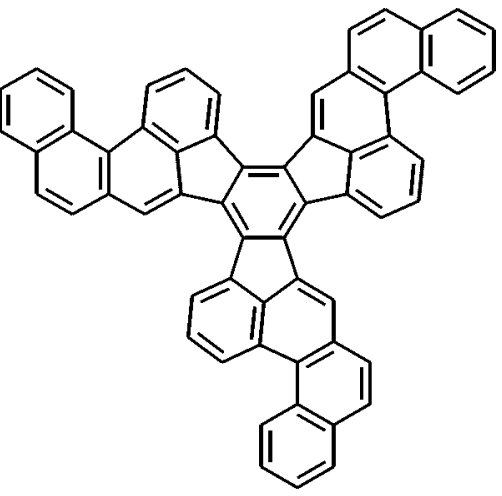

$\mathrm{C}_{60} \mathrm{H}_{30}, \mathrm{C}_{3}$

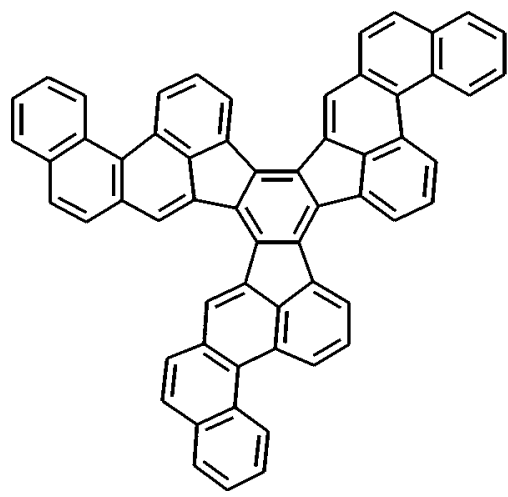

$\mathrm{C}_{60} \mathrm{H}_{30}, \mathrm{C}_{1}$

Figure 2. The "propeller-shaped" $\mathrm{C}_{60}$ progenitor benzo[1,2-e:3,4-e':5,6-e"]tribenzo[1] acephenathrylene $\left(\mathrm{C}_{3}\right.$ symmetry) and its isomer benzo[1,2-e:3,4-e':6,5-e $\left.\mathrm{e}^{\prime \prime}\right]$ tribenzo[1] acephenanthrylene $\left(\mathrm{C}_{1}\right.$ symmetry).

POOR QUALITY

Elemental sulfur should be present in such systems, but it is not known whether $\mathrm{C}_{20} \mathrm{H}_{12}$ forms during algal decay. Formation of glassy carbon in laboratories and graphitization of carbon black requires higher temperatures than the conditions of greenschist facies metamorphism, but the long duration of the metamorphism might offset this drawback. Could $\mathrm{C}_{60}$ form in small amounts under these natural conditions? The answer is not yet known unless one accepts the natural fullerenes as evidence that it does.

\subsubsection{Sudbury}

The search for fullerenes in rocks from the huge Sudbury impact structure was undertaken because it suggested an LDEF kind of event only numerous orders of magnitude bigger. ${ }^{[117]}$ The Sudbury multi-ring, tectonically deformed impact structure in Ontario, Canada is $1.85 \mathrm{Ga}$ in age. ${ }^{[118,119]}$ The Precambrian date is significant because not enough combustible plant-life was then available to sustain the kind of global wildfires which raged following the catastrophic impact at the end of the Cretaceous and which are thought to have produced fullerenes (see section on sedimentary rocks). The estimated diameter of $\sim 180-250 \mathrm{~km}$ of the Sudbury structure is among the largest on Earth. ${ }^{[120-122]}$ The carbon-rich rocks of interest occur within a canoe-shaped $\sim 1600 \mathrm{~m}$ thick sequence of heterolithic breccias of the Onaping Formation ${ }^{[123]}$ 


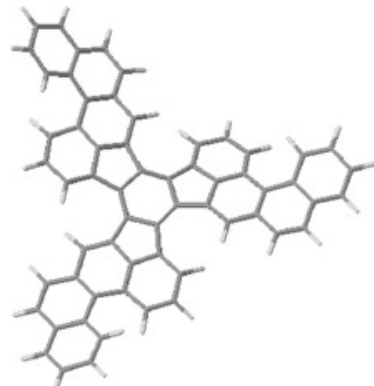

$\mathrm{C}_{60} \mathrm{H}_{30}, \mathrm{C}_{3}$

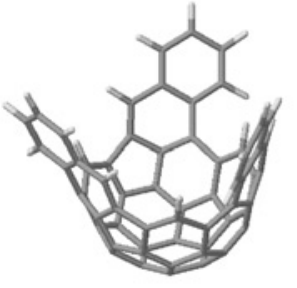

$\mathrm{C}_{60} \mathrm{H}_{18}, \mathrm{C}_{3}$

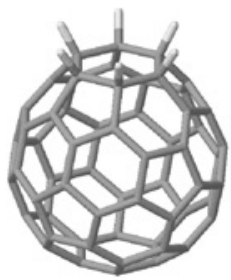

$\mathrm{C}_{60} \mathrm{H}_{6}, \mathrm{C}_{3 x}$

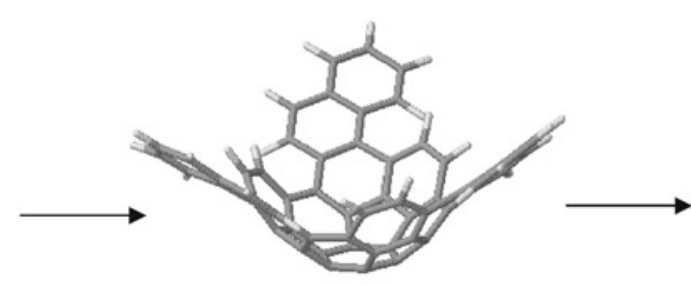

$\mathrm{C}_{60} \mathrm{H}_{24}, \mathrm{C}_{3}$

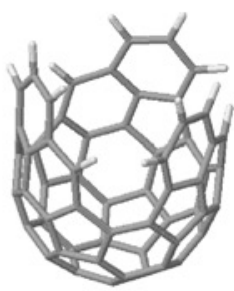

$\mathrm{C}_{60} \mathrm{H}_{12}, \mathrm{C}_{3}$

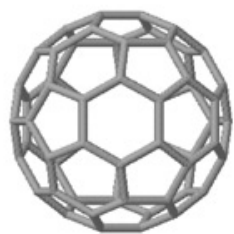

$\mathrm{C}_{60}, \mathrm{I}_{\mathrm{h}}$

Figure 3. Zipping up "the crushed fullerene" $\mathrm{C}_{60} \mathrm{H}_{30}: \mathrm{C}_{60}$ by fifteen-fold, consecutive intramolecular $\mathrm{H}_{2}$ losses and ring closures under MALDI TOF-MS (positive ion mode) conditions ${ }^{[67,69]}$ (Ref. ${ }^{[66]}$ ). All structures were obtained by semiempirical (AM1 and PM3) calculations. Both methods give similar results ${ }^{[67-69,116]}$.

Q4

POOR QUALITY 
which is overlain by $\sim 600 \mathrm{~m}$ of mudstones of the Onwatin Formation, ${ }^{[124]}$ and $\sim 850 \mathrm{~m}$ of wacke-turbidites of the Chelmsford Formation, ${ }^{[124]}$ all making up the Whitewater Group. ${ }^{[125]}$ Figure 4 is a schematic representation of this Group, showing also the traditional subdivision of the Onaping Formation. It was in rocks from the Black Member of this Formation that fullerenes were found in ppm concentrations. ${ }^{[117]}$ It was subsequently reported that the $\mathrm{C}_{60}$ was actually an endohedral molecule with isotopically anomalous He enclosed within the cages. ${ }^{[126]}$ Other investigators have failed to find fullerenes in their samples of the same formation. ${ }^{[127]}$ Table 2 lists the results of all searches for fullerenes in rocks from the Sudbury structure. Clearly some samples contained fullerenes whilst others did not.

The rocks of the Black Member of the Onaping Formation in which the fullerenes were found contain approximately one percent of overwhelmingly elemental carbon. Raman spectra show that the carbon is highly disordered. ${ }^{[127]}$ Various theories about the origin of this carbon exist, but extensive ${ }^{13} \mathrm{C} /{ }^{12} \mathrm{C}$ measurements have now conclusively demonstrated that the Black Member carbon is isotopically the same as carbon from the Onwatin and Chelmsford Formations, hence is biogenic. The carbon proper is not from the impactor, but postdates the formation of the crater. ${ }^{[127]}$ Algal remains, formed within the crater's lake, were later graphitized by low-grade greenschist facies metamorphism. Hence the $\mathrm{C}_{60}$ molecules were not formed during the impact event from some carbon-bearing matter of the impactor or from the very sparse local target sources of carbonates and carbonaceous matter, but were already contained within the impactor prior to its collision with Earth, or were formed much later. This raises a number of salient issues. Did the impactor contain enough fullerenes to explain an estimated $\mathrm{C}_{60}$ content of the Black Member? Why is the fullerene distribution of the Black Member so patchy? Could the fullerenes have survived contact with a superheated atmosphere and hot rocks? What fraction was blasted into the stratosphere to fall back to the Earth's surface at large distances from the crater? Could the $\mathrm{He}$ in $\mathrm{He} @ \mathrm{C}_{60}$ have survived the greenschist metamorphism? None of these were ever significantly discussed.

The estimated pre-deformation, circular diameter of the Onaping Formation is about $50 \mathrm{~km}$ and its thickness about $1 \mathrm{~km}$. This yields a total volume of roughly $2000 \mathrm{~km}^{3}$, somewhat larger than an earlier estimate. ${ }^{[128]}$ The reported $\mathrm{C}_{60}$ contents of Black Member rocks are in the range $1-10 \mathrm{ppm} .{ }^{[117]}$ The only extraterrestrial matter for which $\mathrm{C}_{60}$ was reported were meteorites, samples of which contained from a few to about $100 \mathrm{ppb}_{60}$ (see Table 1). Let us assume a uniform $\mathrm{C}_{60}$ content of $10 \mathrm{ppb}$ for the impactor of which only an estimated $0.1 \mathrm{ppb}$ remained behind at the impact site (from an estimated Ir content at the Chicxulub Cretaceous/Tertiary age impact site, compared to the estimated total, world-wide iridium deposits; Dr. B. C. Schuraytz, private communication, 2000). The remaining $99.9 \mathrm{ppb}$ would have been dispersed globally, like 
589

590

591

592

593

594

595

596

597

598

599

600

601

602

603

604

605

606

607

608

609

610

611

612

613

614

615

616

617

618

619

620

621

622

623

624

625

626

627

628

629

630
CHELMSFORD

ONWATIN

BLACK MEMBER

\section{GRAY MEMBER}

BASAL MEMBER

IGNEOUS COMPLEX

Figure 4. Schematic representation of the Formations of the Whitewater Group rocks of the Sudbury Impact Structure. From bottom to top: Igneous Complex. Then: Basal Member, Gray Member, Green Member (the thin white band above the Gray Member), and Black Member, all of the Onaping Formation. Then: Onwatin Formation and Chelmsford Formation. 
Table 2. Fullerenes in rocks from the Sudbury impact structure.

\begin{tabular}{lcc}
\hline $\begin{array}{l}\text { Sample Location } \\
\text { ONAPING FORMATION }\end{array}$ & $\mathrm{C}_{60}(\mathrm{ppm})$ & Reference \\
\hline BLACK MEMBER & 1 & \\
High Falls $^{\mathrm{a}}$ & $6-7$ & {$[117]$} \\
High Falls & not found & {$[117]$} \\
High Falls $^{\mathrm{b}}$ & 10 & {$[117]$} \\
Onaping River & found & $\mathrm{c}$ \\
Dowling & not found & {$[126]$} \\
Dowling & found & {$[127]$} \\
Capreol & not found & {$[126]$} \\
Capreol & not & {$[127]$} \\
Nelson Lake & not found & {$[127]$} \\
South Chelmsford & not found & {$[127]$} \\
Nickel Offset Road & not found & {$[127]$} \\
GREY MEMBER & & \\
High Falls & not found & {$[127]$} \\
ONWATIN FORMATION & & \\
Dowling & not found & {$[127]$}
\end{tabular}

${ }^{\mathrm{a}}$ Names of sampling locations on the Black Member of the Onaping Formation.

${ }^{\mathrm{b}}$ Eight different rocks from High Falls.

${ }^{\mathrm{c}} \mathrm{He} @ \mathrm{C}_{60}$ reported.

${ }^{\mathrm{d}}$ Three different rocks from Capreol.

iridium in the case of the Chicxulub event. In order for the Black Member to have a uniform $\mathrm{C}_{60}$ content of at least $1 \mathrm{ppm}$, the volume of the impactor must have been $\left\{10^{-6} / 10^{-9}\right\} \times 2000=2 \times 10^{6} \mathrm{~km}^{3}$ and its radius at least on the order of $100 \mathrm{~km}$, clearly outside the estimated impactor radius of $10-20 \mathrm{~km}$ (Dr. B. French, private communication, 2000). Obviously, the fullerene content of the Black Member is too large to be consistent with a maximum dimension of the impactor.

The survival during impact and patchiness of $\mathrm{C}_{60}$ in the Black Member can perhaps be understood in the context of fallback and accumulation of the unconsolidated, still carbon-poor Onaping breccia that eventually became the Black Member rocks. Numerous experimental and theoretical studies of large impacts have demonstrated that significant fractions of large impactors can become scrambled with the target rocks and some impactor matter may be found among the local, so-called fallback material. Most experts on Sudbury have concluded that the fallback layers, i.e. deposits of material that was lifted up only to fall back into the crater, are the Basal, Gray and Green Members of 
the Onaping Formation, all three below the Black Member in which the fullerenes were found. ${ }^{[129]}$ It has also been argued that the rock fragments and glasses of the Black Member were actually stream-carried from outside the central depression into the central depression where redeposition occurred under euxinic aquatic conditions. ${ }^{[127,130]}$ When did the first rains come after the impact? Did they cool the surface sufficiently to allow preservation of fullerenes? Perhaps so; nevertheless the substantial abundance of once-molten glasses in the Onaping rocks is worrisome. Fortunately, the deduced solubility of $\mathrm{C}_{60}$ in water is only on the order of only $10-11 \mathrm{ng} / \mathrm{mL} .^{[131]}$

Arguably the greatest problem for the $\mathrm{He} @ \mathrm{C}_{60}$ origin from the impactor is that helium loss rates as a function of temperature can be calculated from the thermal release experiments carried out with these molecules. ${ }^{[126]}$ When such rates are applied to the temperature range and duration of the greenschist metamorphism, $300-500^{\circ} \mathrm{C}$ during hundreds of thousands of years, it follows that the helium should have been quantitatively lost. Perhaps fullerenes at Sudbury also formed from algal remains late during the metamorphism that would avert the potential problems of heat, pressure, and radiation of the impact environment. Perhaps isotopically anomalous helium, released from older minerals was occluded by the fullerene precursors and later firmly trapped in the fullerene molecules.

\subsubsection{The Bohemian Massif}

At Mitov in the Bohemian Massif, Czech Republic, there occur pillow lavas of andesitic basalt that contain hard solid bitumens with $\mathrm{C}_{60}$ at a level of $0.2 \mathrm{ppm}$ as determined by HPLC and mass spectrometry. ${ }^{[132]} \mathrm{C}_{70}$ was not found. It is thought that algal organic remains of Precambrian age were the parent materials for the bitumens. The highly carbonized material is characterized as glassy carbon. Once again it is remarkable that fullerenes were found in materials with a biologic ancestry in the absence of any evidence that $\mathrm{C}_{60}$ could have come "from the outside". It is this discovery that strengthens the earlier mentioned hypothesis of conversion of certain PAHs to $\mathrm{C}_{60}$ but not $\mathrm{C}_{70}$ during geologic metamorphism.

\subsubsection{Coal}

Coals have been investigated for the production of fullerenes (see for example Ref. ${ }^{[133]}$ ). There are two reasons why one may expect fullerenes to occur in coal. Coal is another material formed by metamorphism of biologic remains and underground fires in coal deposits are common. Analyses are generally encumbered by substantial amounts of organic compounds co-extracted 
with possible fullerenes. $\mathrm{C}_{60}$ fullerene has been reported in a coal from Yunnan province, China. ${ }^{[134]}$

\subsubsection{Summary of Terrestrial Hard Rocks}

There is considerable evidence that $\mathrm{C}_{60}$ molecules are associated at the $0.1-10 \mathrm{ppm}$ level with highly carbonized matter in shungite, in rocks from the Sudbury structure, and from the bitumens at Mitov. Evidence for the occurrence of $\mathrm{C}_{70}$ in these materials is weak. Only at Sudbury was $\mathrm{C}_{60}$ found in rocks from an ancient impact crater and evidence that some, or all of the fullerenes are extraterrestrial. No such claim can be made for the fullerenes reported in shungite and bitumen. How did these form? And did some, or all of the fullerenes at Sudbury perhaps form in the same manner?

The carbons in which the fullerenes were found seem to have one property in common. It has been suggested here that every one these was derived from algal remains via metamorphic carbonization. For the carbon in the Black Member of the Onaping Formation that has been proven ${ }^{[127]}$ but investigators of shungite are divided on the biogenic origin of its carbon. ${ }^{[106]}$ The discoverers of fullerenes in the Czech bitumens claim a biogenic origin for these also. ${ }^{[132]}$ Are there any reasons to expect formation of small quantities of fullerenes from algal remains? As we have argued in Section 3.4.1, biogenic PAHs might have been transformed to $\mathrm{C}_{60}$.

The report that fullerenes at Sudbury contain isotopically anomalous helium seemingly precludes a terrestrial biogenic origin for the fullerenes in the Black Member of the Onaping Formation. However, only 1 in about $10^{5}$ $\mathrm{C}_{60}$ molecules contains a helium atom; therefore a significant fraction of the remaining $\mathrm{C}_{60}$ molecules could be biogenic.

Some samples from Shunga and Sudbury were shown not to contain $\mathrm{C}_{60}$. In one case at Sudbury a fullerene-containing sample was only about $10 \mathrm{~cm}$ removed from a fullerene-free sample. ${ }^{[127]}$ Obviously, the fullerene distribution in these rocks is very patchy. An attractive feature of the hypothesis of PAH-trimerization/dehydrogenation with sulfur is that it may explain this patchyness. ${ }^{[64,116]}$ Only in spots where the correct PAHs and hot sulfur both occurred could fullerenes form at all and perhaps only very inefficiently.

\subsection{Soft Rocks}

\subsubsection{Cretaceous-Tertiary Boundary}

In 1980, Alvarez and his collaborators discovered a thin global layer of clay-like geologic deposits greatly enriched in iridium. ${ }^{[135]}$ They concluded 
that a large extraterrestrial, iridium-rich body had collided with the Earth and that this event had triggered the catastrophic biologic extinctions at that time. The existence of a large buried crater at the tip of the Yucatan peninsula of Mexico was established as early as $1950^{[136]}$ but it was not until 1990 that the crater, widely known as Chicxulub, was firmly identified as the KT impact site. $^{[137]}$ The time of the event is now determined as $65 \mathrm{Ma}$ ago. Whereas the target rocks at Sudbury were mostly igneous and metamorphic with very little limestone, the target at Chicxulub was a thick carbonate platform with seams of sulfates. At Chicxulub there also were no thick elemental carbon-rich rocks.

The search for fullerenes in KTB materials was undertaken because it had been reported that these were rich in soot due to global wildfires following the impact, ${ }^{[138-143]}$ and because it was known that fullerenes form in oxygenstarved sooting flames. ${ }^{[144-146]}$ The disaggregated and powdered samples were extracted with toluene and the filtered solutions were analyzed by HPLC. Because most of these samples were also rich in organic compounds, including PAHs, the fullerene peaks in HPLC were riding on the tails of large organic peaks. This problem was significantly alleviated by the preseparation of organics and fullerenes with a large semi-preparative HPLC column (Heymann et al., 1995). The identification of fullerenes was made on the basis of retention times and UV-VIS spectra. The presence of $\mathrm{C}_{70}$ in some chromatograms was especially important because it seemed unlikely that false positives would be obtained for two fullerenes.

The first hint that $\mathrm{C}_{60}$ was present in a small sample from the KTB at Woodside Creek, New Zealand was presented at the conference on New Developments Regarding the KT Event and Other Catastrophes in Earth History, 1993. ${ }^{[147]}$ No fullerenes were found in the massive limestones above and below the KTB clay at Woodside Creek. Subsequently, fullerenes were studied in much larger samples and were found to be present or absent at 13 different KTB sites around the world. ${ }^{[58,74,148-154]}$ One of the discoveries was reported in note 13 of Becker et al. ${ }^{[117]}$ The location of the site was not given, but it is at Gubbio, Italy (Dr. L. Becker and Dr. T. Bunch, personal communication, 1994). All results are presented in Table 3. The $\mathrm{C}_{60}$ contents range from essentially zero to $16 \mathrm{ppb}$. $\mathrm{C}_{70}$, when present was typically between 0.2 and 0.3 times $\mathrm{C}_{60}$.

It was suggested that the fullerenes at the KTB had formed by oxygen-starved wildfires following the event. Since most of the KTB clays studies are relatively shallow water deposits formed near landmasses, it was also suggested that the fullerenes were co-deposited with the soot particles on which they were absorbed. It was also suggested that the fullerenes came from local fires and not from a worldwide deposit. It is not understood why fullerenes were not present at some locations. The most logical explanation is that the local conditions were unfavorable for fullerene-producing wildfires. 
Table 3. Fullerenes in samples from Cretaceous Tertiary Boundary sites.

\begin{tabular}{|c|c|c|c|}
\hline Site Name & Country & $\mathrm{C}_{60}(\mathrm{ppm})$ & Reference \\
\hline Woodside Creek $^{\mathrm{a}}$ & New Zealand & 2.17 & {$[157]$} \\
\hline Woodside Creek & New Zealand & 2.74 & [157] \\
\hline Woodside Creek & New Zealand & 2.5 & {$[157]$} \\
\hline Woodside Creek & New Zealand & 4.7 & [157] \\
\hline Woodside Creek & New Zealand & 5.4 & {$[157]$} \\
\hline Woodside Creek ${ }^{\mathrm{b}}$ & New Zealand & 0.325 & {$[157]$} \\
\hline Woodside Creek ${ }^{\mathrm{c}}$ & New Zealand & 2.48 & [157] \\
\hline Flaxbourne River ${ }^{\mathrm{d}}$ & New Zealand & 0.556 & {$[157]$} \\
\hline Flaxbourne River & New Zealand & 1.14 & {$[157]$} \\
\hline Flaxbourne River & New Zealand & 0.0058 & [157] \\
\hline Flaxbourne River & New Zealand & 2.3 & {$[157]$} \\
\hline Flaxbourne River & New Zealand & 1.84 & {$[157]$} \\
\hline Flaxbourne River ${ }^{\mathrm{c}}$ & New Zealand & 15.7 & {$[148,149]$} \\
\hline Flaxbourne River & New Zealand & 11.9 & {$[148,149]$} \\
\hline Caravaca & Spain & 11.9 & {$[74,151,152]$} \\
\hline Caravaca $^{\mathrm{c}}$ & Spain & 2.7 & {$[74,151,152]$} \\
\hline Sumbar-4 & Turkmenistan & 4.0 & {$[74,151,152]$} \\
\hline Sumbar-5 & Turkmenistan & 1.2 & {$[74,151,152]$} \\
\hline Stevns Klint & Denmark & 2.17 & {$[74,151,152]$} \\
\hline Stevns Klint & Denmark & 0.9 & {$[74,151,152]$} \\
\hline Elendgraben & Austria & 0 & {$[74,151,152]$} \\
\hline Tetri Tskaro & Georgia & 0 & {$[74,151,152]$} \\
\hline Brazos River ${ }^{\mathrm{e}}$ & Texas, USA & 0 & {$[153,154]$} \\
\hline Gubbio $^{\text {f }}$ & Italy & detected & [117] \\
\hline Raton Basin & Colorado, USA & detected & [117] \\
\hline Stevns Klint ${ }^{\mathrm{g}}$ & Denmark & detected & [126] \\
\hline Woodside Creek & New Zealand & 0 & [126] \\
\hline
\end{tabular}

${ }^{\mathrm{a}}$ This material came from high on a hillside at Woodside Creek at which no sampling had ever been done before.

${ }^{\mathrm{b}}$ This sample came from the southern bank of the creek, at river level.

${ }^{\mathrm{c}}$ Demineralized samples.

${ }^{\mathrm{d}}$ This material came from a location at Flaxbourne River at which no sampling had ever been done before.

${ }^{\mathrm{e}}$ No fullerenes were found in 55 samples studied.

feference \# 13 in Becker et al. ${ }^{[117]}$

${ }^{\mathrm{g}}$ Also higher fullerenes reported. 
These results and discussions were questioned on the grounds that the oxygen content of the atmosphere at the time of the Chicxulub event was too high and that no fullerenes were found in a sample from burned wood associated with the 1993 Malibu Fires. ${ }^{[155]}$ However, oxygen is needed to remove hydrogen from the fullerene precursors in flame-produced fullerenes. The "burned wood argument" overlooks the deduction that the KTB fires started only after the combustible biota had become dry. ${ }^{[138-143]}$ The wood burned by the Malibu Fires was green. Stronger evidence against the wildfire hypothesis was provided when it was found that preterrestrial isotopically anomalous He associated with fullerenes occurs in the Raton and Stevns Klint samples. ${ }^{[155]} \mathrm{A}$ fullerene molecule cannot be both terrestrial and preterrestrial. One problem with this argument is that there is no direct evidence that the helium atoms are actually inside these $\mathrm{C}_{60}$ molecules.

A quite serious objection was raised in a paper with the grossly misleading title "There are no fullerenes in the K-T boundary layer". ${ }^{[156]}$ The authors reported no traces of $\mathrm{C}_{60}$ or $\mathrm{C}_{70}$ in a single sample from the Woodside Creek site. They suggested that earlier HPLC results measured only "a mixture of hydrocarbons". However, there are questions about this study also. While the large number of positive results both by HPLC and later by LDMS of Table 3 are no guarantee that fullerenes actually occur in KTB clays, a single measurement on a $20 \mathrm{~g}$ sample from the riverside location at Woodside Creek is not very convincing evidence for "no fullerenes in the K-T boundary layer". It was not explained by the critique why the so-called "false" $\mathrm{C}_{60}$ peak in the HPLC chromatograms of the positive results sticks out from the tail of "a mixture of hydrocarbons". ${ }^{[148]}$ The probable explanation is simply that $\mathrm{C}_{60}$ has an exceptionally large molar extinction at $336 \mathrm{~nm}$, much larger than that of hydrocarbons. It was not explained either by the critique why several of the KTB extracts show not only $\mathrm{C}_{60}$ at the expected retention time and with its known UV-VIS spectrum but also $\mathrm{C}_{70}$ at the expected retention time and with its known UV-VIS spectrum. This seems too much of a coincidence to be explained away with mixtures of hydrocarbons. The authors of the critique are also concerned about the "known high oxidative instability of fullerenes". That is a puzzling statement because nobody has yet shown that $\mathrm{C}_{60}$ in the ground state reacts detectably with molecular oxygen in the ground state.

\subsubsection{Permian-Triassic Boundary}

It has long been known that the extinctions that define the PTB boundary $251 \mathrm{Ma}$ ago killed more than $90 \%$ of all marine species, about $70 \%$ of terrestrial vertebrate genera and most land plants. Until recently there was no direct evidence that these catastrophic extinctions had been caused by the aftermath of 
a large meteorite impact on Earth. There is no significant global iridium anomaly at the PTB and evidence for shocked minerals is weak. However, if $\mathrm{C}_{60}$ and $\mathrm{C}_{70}$ fullerenes with encapsulated isotopically anomalous helium were found, the case for an impact-caused PTB extinction could be compared with that of the KTB event at Chicxulub. In 1999, Chijiwa et al. reported the occurrence 10$20 \mathrm{ppt}$ of these fullerenes in a PTB sediment from Inuyama, Japan. ${ }^{[157]}$ Subsequently Becker and coworkers ${ }^{[158]}$ studied fullerenes and their possible encapsulated noble gases from PTB sites at Meishan (China), Sasayama (Japan), and Bálvány (Hungary). The analysis of extracts by LDMS showed peaks at $720 \mathrm{amu}\left(\mathrm{C}_{60}{ }^{+}\right)$and $840 \mathrm{amu}\left(\mathrm{C}_{70}{ }^{+}\right)$for the Meishan and Sasayama samples. No ions due to $\mathrm{C}_{60}$ or $\mathrm{C}_{70}$ were detected in the Bálvány sample, which, however, produced peaks in the range 780-2400 amu. Concentrations of the fullerenes were not reported. Isotopically anomalous He was reported in the Meishan and Sasayama samples. No evidence was presented that the helium atoms were actually inside the fullerene molecules.

These conclusions were soon questioned. Braun et al. ${ }^{[159]}$ criticized the absence of sampling descriptions from the stratigraphic layers, sample amounts and homogeneity, and the huge discrepancy between the ppb amounts of fullerenes found by Becker et al. at Sasayama as against the ppt amounts reported by Chijiwa at the Inuyama site. At the time of writing of this review, there was no reply available from the Becker team. Farley and Mukhopadhyay found no extraterrestrial $\mathrm{He}$ in fifteen aliquots from a sample from Bed 25 at Meishan and six such samples from an equivalent bed at Shangsi, China. ${ }^{[160]}$ Isozaki pointed out that the PTB horizon is missing at the Sasayama section and that the ${ }^{3} \mathrm{He}$-enriched sample of Becker et al. has actually come from at least $0.8 \mathrm{~m}$ below the PTB. ${ }^{[161]}$ Becker and Poreda replied that Farley and Mukhopadhyay used a faulty experimental technique and that their own interpretation of where the PTB at Sasayama is differs from that of Isozaki. ${ }^{[162]}$ Perhaps both answers are valid, but it remains worrisome that only one research group has been able thus far to find isotopically anomalous helium in samples from meteorites, and from the Sudbury, Chicxulub and end-Permian events.

\section{ODDBALLS}

\subsection{Fulgurite}

Fulgurites are glassy rocks that form from inorganic minerals when lightning strikes the ground. In five fulgurite samples studied, one contained $C_{60}$ and $C_{70}$ as determined by laser-desorption mass spectrometry. ${ }^{[163]}$ Presumably, carbon for the fullerenes was from biologic remains in the ground. The conditions of temperature and pressure during the lightning stroke are extreme and hugely 
outside any laboratory conditions of fullerene synthesis. It is therefore impossible to reconstruct how the fullerenes in the one fulgurite formed.

\subsection{Chinese Ink Sticks}

Chinese ink sticks, used for calligraphy, are made from soot obtained by the slow burning of oils, mixed with animal glue, and then dried. Because fullerenes had been shown to form in flames, a search for $\mathrm{C}_{60}$ and $\mathrm{C}_{70}$ in such materials was undertaken by solvent extraction and HPLC. ${ }^{[164,165]}$ The amounts reported were up to 0.1 (weight) \%. Two subsequent studies found much less fullerenes ( $3 \mathrm{ppm}$ at most), which also suggested that the $\mathrm{C}_{60}$ content of older sticks was less than that of younger sticks.

\subsection{Dinosaur Eggs}

$\mathrm{C}_{60}$ but not $\mathrm{C}_{70}$ was reportedly found in a $70 \mathrm{~mA}$ old fossilized dinosaur egg from Xixia, China. ${ }^{[166]}$

\subsection{Tree Char}

Char collected from a Norway spruce struck by lightning was studied for the presence of fullerenes but none were found ${ }^{[167]}$ Because of the presence of much water the conditions during the formation of tree char are very different from those of fulgurite formation. Temperatures and pressures are much lower because much of the lightning's energy is converted to steam.

\section{BIOGENIC FULLERENES?}

We have pointed out in an earlier section that one of the fundamental issues about naturally occurring fullerenes is whether these could form in the solid state. We have also noted that fullerenes can form by the "zip-up" of PAHs and that algal remains were the most likely source for the carbons at Shunga, Sudbury, and Mitov. Here we will briefly comment on the biological aspects of the hypothesis of fullerene formation in the solid state.

PAHs with as many as sixty or more carbon atoms are not known to occur in nature ${ }^{[168]}$ but may have escaped detection owing to their anticipated cumbersome analysis ${ }^{[169]}$ due to their exceedingly low solubility in common extraction solvents. Nevertheless, fullerenes in rocks must have formed primarily from smaller molecules. 

1000 shales (Standard Reference Materials Program). Living algae contain hopa1001 noids, steroids, and sterols whose structures have external pentagonal carbon 1002 rings $^{[179-181]}$ but it is not clear how these evolve during diagenesis and 1003 metamorphism, especially what happens to their $-\mathrm{CH}_{3}$ and larger side-chains. 1004 Pyrolysis of lignitic matter apparently can form molecules similar to $\mathrm{C}_{20} \mathrm{H}_{14}$ or 1005 the molecules used for the zip-up of $\mathrm{C}_{60}$ above. Perhaps suitable building blocks 1006 do form in algal remains during the greenschist facies metamorphism of the 1007 rocks at Shunga and Sudbury and during the high emplacement temperatures of 1008 the bitumens at Mitov, estimated to have been in the range $800-1000^{\circ} \mathrm{C}$. 
Elemental sulfur $\left(\mathrm{S}_{8}\right)$ is common in sediments either from bacterial activity or from weathering of sulfides such as pyrrhotite. Hence the formation of large PAHs from the smaller ones should be possible to occur at relatively low temperatures during early metamorphism. The serious enigma is how fullerenes might form from these larger precursors under conditions that are a far cry from the laser-ablation zip-ups in the laboratories. Substantial dehydrogenation and aromatization of biological remains during rock metamorphism is well established, but is it sufficient for zip-ups of precursors to fullerenes? Perhaps elemental sulfur or certain oxides play a role in the removal of hydrogen, and dehydrogenation and zip-ups in natural settings are perhaps catalytically accelerated by inorganic minerals. ${ }^{[182]}$

Obviously the journey from algae to fullerenes is replete with pitfalls and perhaps detours but it is important to remember that the reported amounts of $\mathrm{C}_{60}$ in the Mitov bitumens of $200 \mathrm{ppb}$ is some five to six orders of magnitude smaller than the fullerene concentrations routinely achieved by carbon condensation and in soot from controlled hydrocarbon burning. Much also needs to be learned about the photochemistry of biologic remains in the upper water column and a possible role of unpaired electrons, which are abundantly present in kerogens and carbonaceous matter, has to be established.

\section{REFERENCES}

1. Kroto, H.W.; Heath, J.R.; O’Brien, S.C.; Curl, R.F.; Smalley, R.E. Buckminsterfullerene. Nature 1985, 318, 162-163.

2. Krätschmer, W.; Lamb, L.D.; Fostiropoulos, K.; Huffman, D. Solid $\mathrm{C}_{60}$ : a new form of carbon. Nature 1990, 347, 354-358.

3. Buseck, P. Geologic fullerenes: review and analysis. Earth Planet Sci. Lett. 2002, 203, 781-792.

4. Becker, L.; Bada, J.L.; Winans, R.E.; Bunch, T.E. Fullerenes in Allende meteorite. Nature 1994a, 372, 507.

5. Ash, R.D.; Russell, S.S.; Wright, I.P.; Pillinger, C.T. Minor high temperature components confirmed in carbonaceous chondrites by stepped combustion using a new sensitive static mass spectrometer. Lunar and Planetary Science XXII; Lunar and Planetary Institute: Houston TX, USA, 1993; 35-36.

6. Gilmour, I.; Russell, S.S.; Newton, J.; Pillinger, C.T.; Arden, J.W.; Dennis, T.J.; Hare, J.P.; Kroto, H.W.; Taylor, R.; Walton, D.R.M. A search for the presence of $\mathrm{C}_{60}$ as an interstellar grain in meteorites. Lunar and Planetary Science XXII; Lunar and Planetary Institute: Houston TX, USA, 1993; 445-446. 
7. DeVries, M.S.; Reihs, K.; Wendt, H.R.; Golden, W.G.; Hunziker, H.E.; Fleming, R.; Peterson, E.; Chang, S. A search for $\mathrm{C}_{60}$ in carbonaceous chondrites. Geochim. Cosmochim. Acta 1993, 57, 933-935.

8. Heymann, D. Search for extractable fullerenes in the Allende meteorite. Lunar and Planetary Science XXV; Lunar and Planetary Institute Houston: TX, USA, 1995a; 595-596.

9. Heymann, D. Search for extractable fullerenes in the Allende meteorite. Meteoritics 1995b, 30, 436-438.

10. Heymann, D. Fullerenes and fulleranes in meteorites revisited. Astrophys. J. 1997, 489, L111-L114.

11. Braga, M.; Larsson, S.; Rosen, A.; Volosov, A. Electronic transitions in $\mathrm{C}_{60}$-on the origin of the strong interstellar absorption at $217 \mathrm{~nm}$. Astron. Astrophys. 1991, 245, 232-238.

12. Van Der Zwet, G.P.; Allamandola, L.J. Polycyclic aromatic-hydrocarbons and the diffuse interstellar bands. Astron. Astrophys. 1985, 146, 76-80.

13. Léger, A.; D'Hendecourt, L. Are polycyclic aromatic-hydrocarbons the carriers of the diffuse interstellar bands in the visible?. Astron. Astrophys. 1985, 146, 81-85.

14. Crawford, M.K.; Tielens, A.G.G.M.; Allamandola, L.J. Ionized polycyclic aromatic-hydrocarbons and the diffuse interstellar bands. Astrophys. J. Lett. 1985, 293, L45-L48.

15. Ehrenfreund, P.; Charnley, S.B. Organic molecules in the interstellar medium, comets, and meteorites: a voyage from dark clouds to the early earth. Ann. Rev. Astron. Astr. 2000, 38, 427-483.

16. Heath, J.R.; Curl, R.F.; Smalley, R.E. The UV absorption spectrum of $\mathrm{C}_{60}$ (buckminsterfullerene): a narrow band at $3860 \AA$. J. Chem Phys. 1987, 87, 4236-4238.

17. Léger, A.; D’Hendecourt, L.; Verstraete, L.; Schmidt, W.F. Remarkable candidates for the carrier of the diffuse interstellar bands: $\mathrm{C}_{60}{ }^{+}$and other polyhedral carbon ions. Astron. Astrophys. 1988, 203, 145-148.

18. Foing, B.H.; Ehrenfreund, P. Detection of two interstellar absorption bands coincident with spectral features of $\mathrm{C}_{60}{ }^{+}$. Nature 1994, 369, 296-298.

19. Foing, B.H.; Ehrenfreund, P. New evidence for interstellar $\mathrm{C}_{60}{ }^{+}$. Astron. Astrophys. 1997, 317, L59-L62.

20. Ehrenfreund, P.; Foing, B.H. Search for fullerenes and PAHS in the diffuse interstellar medium. Planet. Space Sci. 1995, 43, 1183-1187.

21. Ehrenfreund, P.; Foing, B.H. Fullerenes in space. Adv. Space Res. 1997, 19, 1033-1042.

22. Sonnentrucker, P.; Cami, J.; Ehrenfreund, P.; Foing, B.H. The diffuse interstellar bands at 5797, 6379 and $6613 \AA$ A.-ionization properties of the carriers. Astron. Astrophys. 1997, 327, 1215-1221. 
23. Fulara, J.; Krelowski, J. Origin of diffuse interstellar bands: spectroscopic studies of their possible carriers. New Astron. Rev. 2000, 44, 581-597.

24. Galazutdinov, G.A.; Krelowski, J.; Musaev, F.A.; Ehrenfreund, P.; Foing, B.H. On the identification of the $\mathrm{C}_{60}{ }^{+}$, interstellar features. Mon. Not. R. Astron. Soc. 2000, 317, 750-758.

25. Webster, A.S. Comparison of a calculated spectrum of $\mathrm{C}_{60} \mathrm{H}_{60}$ with the unidentified astronomical IR emission features. Nature 1991, 352, 412-414.

26. Webster, A.S. Fulleranes, fullerenes and the interstellar extinction. Astron. Astrophys. 1992a, 257, 750-756.

27. Webster, A.S. Fullerenes, fulleranes and the diffuse interstellar bands. Mon. Not. R. Astron. Soc. 1992b, 255, P41-P42.

28. Webster, A.S. The vibrations of $\mathrm{C}_{60} \mathrm{H}_{60}$ and the unidentified infraredemission. Mon. Not. R. Astron. Soc. 1993a, 264, 121-131.

29. Webster, A.S. The fullerane $\mathrm{C}_{60} \mathrm{H}_{2}$ and the interstellar extinction. Mon. Not. R. Astron. Soc. 1993b, 263, L55-L58.

30. Webster, A.S. The interstellar extinction curve and the absorption spectra of two fulleranes. Mon. Not. R. Astron. Soc. 1997, 288, 221-224.

31. Jenniskens, P.; Mulas, G.; Poceddu, I.; Benvenuti, P. Diffuse interstellar bands near $9600 \AA$. not due to $\mathrm{C}_{60}{ }^{+}$yet. Astron. Astrophys. 1977, 327, 337-341.

32. Moutou, C.; Sellgren, K.; Verstraete, L.; Léger, A. Upper limit on $\mathrm{C}_{60}$ and $\mathrm{C}_{60}{ }^{+}$features in the ISO-SWS spectrum of the reflection nebula NGC 7023. Astron. Astrophys. 1999, 347, 949-956.

33. Snow, T.P.; Seab, C.G. A search for interstellar and circumstellar $\mathrm{C}_{60}$. Astron. Astrophys. 1989, 213, 291-294.

34. Somerville, W.B.; Bellis, J.G. An astronomical search for the molecule $\mathrm{C}_{60}$. Mon. Not. R. Astr. Soc. 1991, 240, P41-P46.

35. Sassara, A.; Zerza, G.; Chergui, M.; Leach, S. Absorption wavelengths and bandwidths for interstellar searches of $C_{60}$ in the $2400-4100 \AA$. region. Astrophys. J. Suppl. 2001, S135, 263-273.

36. Justannont, K.; Barlow, M.J.; Skinner, C.J.; Roche, P.F.; Aitken, D.K.; Smith, C.H. Mid-infrared spectroscopy of carbon-rich post-AGB objects and detection of the PAH molecule chrysene. Astron. Astrophys. 1996, 309, 612-628.

37. Garcia-Lario, P.; Manchado, A.; Ulla, A.; Manteiga, M. Infrared space observatory observations of IRAS 16594-4565: a new proto-planetary nebula with a strong 21 micron dust feature. Astrophys. J. 1999, 513, 941-946.

38. Kroto, H.W. The role of linear and spheroidal carbon molecules in interstellar grain formation. Ann. Phys. (Paris) 1989, 14, 169-179.

39. Kroto, H.W. Smaller carbon species in the laboratory and space. Int. J. Mass Spectrom. 1994, 138, 1-15. 
40. Kroto, H.W.; Jura, M. Circumstellar and interstellar fullerenes and their analogs. Astron. Astrophys. 1992, 263, 275-280.

41. Kroto, H.W.; Walton, D.R.M. Polyynes and the formation of fullerene. Phil. Trans. R. Soc. Lond. 1993, A343, 103-112.

42. Kroto, H.W.; Heath, J.R.; O’Brien, S.C.; Curl, R.F.; Smalley, R.E. Long carbon chain molecules in circumstellar shells. Astrophys. J. 1987, 314, 352-355.

43. Herlin, N.; Bohn, I.; Reynaud, C.; Galvez, A.; Rouzaud, J.N. Nanoparticles produced by laser pyrolysis of hydrocarbons: analogy with carbon cosmic dust. Astron. Astrophys. 1998, 330, 1127-1135.

44. Scott, A.; Duley, W.W.; Pinho, G.P. Polycyclic aromatic hydrocarbons and fullerenes as decomposition products of hydrogenated amorphous carbon. Astrophys. J. 1997, 489, L193-L195.

45. Bohme, D.K. PAH and fullerene ions and ion/molecule reactions in interstellar and circumstellar chemistry. Chem. Rev. 1992, 92, 14871508.

46. Petrie, S.; Javahery, G.; Bohme, D.K. Experimental results for ionmolecule reactions of fullerenes-implications for interstellar and circumstellar chemistry. Astron. Astrophys. 1993, 271, 662-674.

47. Petrie, S.; Bohme, D.K. Generation and hydrogenation of adjacentpentagon fullerenes-astrochemical considerations. Mon. Not. R. Astron. Soc. 1994a, 268, 938-942.

48. Petrie, S.; Bohme, D.K. Formation and charge-separation reactions of large molecular dications within interstellar clouds - consequences for cold cloud chemical evolution. Mon. Not. R. Astron. Soc. 1994b, 268, 103-108.

49. Petrie, S.; Bohme, D.K. Laboratory studies of ion/molecule reactions of fullerenes: chemical derivatization of fullerenes within dense interstellar clouds and circumstellar shells. Astrophys. J. 2000, 540, 869-885.

50. Heymann, D. Buckminsterfullerene $\mathrm{C}_{60}$ and siblings: their deduced properties as traps for inert gas atoms. Lunar and Planetary Science XVII; Lunar and Planetary Institute: Houston, TX, USA, 1986; 337-338.

51. Lewis, R.S.; Ming, T.; Wacker, J.F.; Anders, E.; Steel, E. Interstellar diamonds in meteorites. Nature 1987, 326, 160-162.

52. Heymann, D. On the chemical attack of fullerene, soot, graphite, and sulfur with hot perchloric acid. Carbon 1991, 29, 684-685.

53. Heymann, D.; Chibante, F. Reaction of $\mathrm{C}_{60}, \mathrm{C}_{70}, \mathrm{C}_{76}, \mathrm{C}_{78}$ and $\mathrm{C}_{84}$ with ozone at $23.5^{\circ} \mathrm{C}$. Recl. Trav. Chim. Pays-Bas 1993, 112, 639-642.

54. Becker, L.; Bunch, T.E.; Allamandola, L.J. Higher fullerenes in the Allende meteorite. Nature 1999, 400, 227-228. 
55. Becker, L.; Bada, J.L.; Bunch, T.E. PAH's, fullerenes and fulleranes in the Allende meteorite. Lunar and Planetary Science XXVI; Lunar and Planetary Institute: Houston, TX, USA, 1995; 423-424.

56. Becker, L.; Bunch, T.E. Fullerenes, fulleranes and polycyclic aromatic hydrocarbons in the Allende meteorite. Meteoritics Planet. Sci. 1997, 32, 479-487.

57. Becker, L.; Poreda, R.J.; Bunch, T.E. Fullerenes and noble gases in the Murchison and Allende meteorites. Lunar and Planetary Science XXXI; Lunar and Planetary Institute: Houston, TX, USA, 2000a; Vol. 1803 (CD ROM).

58. Becker, L.; Poreda, R.J.; Bunch, T.E. Fullerenes: an extraterrestrial carbon carrier phase for noble gases. Proc. Natl Acad. Sci. USA 2000b, 97, 2997-2983.

59. Wieler, R.; Anders, E.; Baur, H.; Lewis, R.S.; Signer, P. Noble gases in "phase Q": Closed-system etching of an Allende residue. Geochim. Cosmochim. Acta 1991, 55, 1709-1722.

60. Smith, P.P.K.; Buseck, P. High resolution transmission electron microscopy of an Allende acid residue. Meteoritics 1980, 15, 368-369.

61. Smith, P.P.K.; Buseck, P. Graphitic carbon in the Allende meteorite: a microstructural study. Science 1981, 212, 322-324.

62. Vis, R.D.; Mrowiec, A.; Kooyman, P.J.; Matsubara, K.; Heymann, D. Microscopic search for the carrier phase Q of the trapped planetary noble gases in Allende, Leoville, and Vigarano. Meteoritics Planet. Sci. 2002, 37, 1391-1400.

63. Taylor, R.; Langley, G.J.; Kroto, H.W.; Walton, D.R.M. Formation of $\mathrm{C}_{60}$ by pyrolysis of naphthalene. Nature 1993, 366, 728-731.

64. Sarobe, M.; Fokkens, R.H.; Cleij, T.J.; Jenneskens, L.W.; Nibbering, N.M.M.; Stas, W.; Versluis, C. $\mathrm{S}_{8}$-mediated cyclotrimerization of 4,5dihydrobenz[1] acephenanthrylene:trinaphtodecacyclene $\left(\mathrm{C}_{60} \mathrm{H}_{30}\right)$ isomers and their propensity towards cyclodehydrogenation. Chem. Phys. Lett. 1999a, 313, 31-39.

65. Sarobe, M. Polycyclic Aromatic Hydrocarbons under High Temperature Conditions; Utrecht University: Utrecht, The Netherlands, 1998; Ph.D. Dissertation.

66. Boorum, M.M.; Vasil'ev, Y.V.; Drewello, T.; Scott, L.T. Groundwork for rational synthesis of $\mathrm{C}_{60}$ : cyclodehydrogenation of a $\mathrm{C}_{60} \mathrm{H}_{30}$ polyarene. Science 2001, 294, 828-831.

67. Gómez-Lor, B.; Koper, C.; Fokkens, R.H.; Vlietstra, E.J.; Cleij, T.J.; Jenneskens, L.W.; Nibbering, N.M.M.; Echavarren, A.M. Zipping up the 'crushed fullerene' $\mathrm{C}_{60} \mathrm{H}_{30}: \mathrm{C}_{60}$ by fifteen intramolecular $\mathrm{H}_{2}$ losses. Chem. Comm. 2002, 370-371. 
68. Koper, C. Non-Alternant Polycyclic Hydrocarbons Versus Closed Carbon Surfaces; Utrecht University: Utrecht, The Netherlands, 2003; Ph.D. Dissertation.

69. Koper, C.; Ruiz M.; de Frutos, Ó.; González-Cantalapiedra, E.; Fokkens, R.H.; Nibbering, N.M.M.; Cárdenas, D.J.; Santos, A.; Gómez-Lor, B.; Jenneskens, L.W.; Echavarren, A.M. Benzo[1,2-e:4-e':5,6-e" $]$ tribenzo [1]acephenanthrylene $\left(\mathrm{C}_{60} \mathrm{H}_{30}\right)$ : a progenitor of $\mathrm{C}_{60}$. Its synthesis by palladium-catalyzed arylation and stepwise conversion into $\mathrm{C}_{60}$. Chem. Eur. J. 2003, in press.

70. Bajt, S.; Chapman, H.N.; Flynn, G.J.; Keller, L.P. Carbon characterization in interplanetary dust particles with a scanning transmission X-ray microscope. Lunar and Planetary Science XXVII; Lunar and Planetary Institute: Houston, Texas USA, 1996a; 57-58.

71. Bajt, S.; Chapman, H.N.; Flynn, G.J.; Keller, L.P. A possibility of the presence of $\mathrm{C}_{60}$ in interplanetary dust particles. Abstract for the Meeting of the Meteoritical Society, Berlin, 1996b.

72. Becker, L.; Poreda, R.J. Fullerenes and interplanetary dust (IDPs) in the phanerozoic. Geochim. Cosmochim. Acta 2002, 66 (15A), A61.

73. Radicati Di Brozolo, F.; Bunch, T.E.; Fleming, R.H.; Macklin, J. Observation of fullerenes in an LDEF impact crater. Nature 1994, 369, 37-40.

74. Heymann, D.; Chibante, L.P.F.; Brooks, R.R.; Wolbach, W.S.; Smit, J.; Korochantsev, A.; Nazarov, M.A.; Smalley, R.E. Fullerenes of possible wildfire origin in cretaceous-tertiary boundary sediments. In The Cretaceous-Tertiary Event and Other Catastrophes in Earth History; Ryder, G., Fastovsky, D., Gartner, S., Eds.; Geological Society of America Special Paper 307; 1996a; 453-464.

75. Epstein, S.; Taylor, H.P. Jr. The concentration and isotopic composition of hydrogen, carbon and silicon in Apollo 11 lunar rocks and minerals. Proc. Apollo 11 Lunar. Sci. Conf. 1970, 1085-1096.

76. Friedman, I.; Gleason, J.D.; Hardcastle, K. Water, hydrogen, deuterium, carbon and ${ }^{13} \mathrm{C}$ content of selected lunar material. Proc. Apollo 11 Lunar Sci. Conf. 1970, 1103-1110.

77. Kaplan, I.R.; Smith, J.W.; Ruth, E. Carbon and sulfur concentration and isotopic composition in Apollo 11 lunar samples. Proc. Apollo 11 Lunar. Sci. Conf. 1970, 1317-1330.

78. Moore, C.B.; Gibson, E.K.; Larimer, J.W.; Lewis, C.F.; Nichiporuk, W. Total carbon and nitrogen abundances in Apollo 11 lunar samples and selected achondrites and basalts. Proc. Apollo 11 Lunar. Sci. Conf. 1970, 1375-1382.

79. Zhang, B.L.; Wang, C.Z.; Ho, K.M. Thermal disintegration of carbon fullerenes. Phys. Rev. 1993, B 48, 11381-11384. 
80. Monthioux, M.; Lavin, J.G. The graphitizability of fullerenes and related textures. Carbon 1994, 32, 335-343.

81. Ugarte, D. High-temperature behavior of "fullerene black". Carbon 1994, 32, 1245-1248.

82. Wan, Z.; Christian, J.F.; Anderson, S.L. Collision energy and impact parameter dependence for endohedral complex formation, fragmentation and charge transfer $\left(\mathrm{C}_{60}\right)$. J. Chem. Phys. 1992a, 96, 3344-3347.

83. Wan, Z.; Christian, J.F.; Anderson, S.L. Collision of $\mathrm{Li}^{+}$and $\mathrm{Na}^{+}$with $\mathrm{C}_{60}{ }^{-}$insertion, fragmentation, and thermionic emission. Phys. Rev. Lett. 1992b, 96, 1352-1355.

84. Hveplund, P.; Andersen, L.H.; Haugen, H.K.; Lindhard, J.; Lorents, D.C.; Malhotra, R.; Ruoff, R. Dynamical fragmentation of $\mathrm{C}_{60}$ ions. Phys. Rev. Lett. 1992, 69, 1915-1918.

85. Busman, H.G.; Lill, T.; Reif B.; Herterl, I.V. Collision induced fragmentation and resilience of scattered $\mathrm{C}_{60}{ }^{+}$fullerenes. Surface Sci. 1992, 272, 146-153.

86. Volpel, R.; Hofmann, G.; Steidl, M.; Stenke, M. Ionization and fragmentation of fullerene ions by electron impact. Phys. Rev. Lett. 1993, 71, 3439-3441.

87. Cornett, D.S.; Amster, I.J.; Duncan, M.A.; Rao, A.M.; Eklund, P.C. Laser desorption mass spectrometry of photopolymerized $\mathrm{C}_{60}$ films. J. Phys. Chem. 1993, 97, 5036-5039.

88. Yamawaki, H.; Yoshida, M.; Kakudate, Y.; Usuba, S.; Yokoi, H.; Fujiwara, S.; Aoki, K.; Ruoff, R.; Malhotra, R.; Lorents, D. Infrared study of vibrational property and polymerization of $\mathrm{C}_{60}$ and $\mathrm{C}_{70}$ under pressure. J. Phys. Chem. 1993, 97, 11161-11163.

89. Heymann, D. Search for fullerenes in lunar fines 10084 and 79261. Meteoritics Planet. Sci. 1996a, 31, 362-364.

90. Buseck, P.R.; Tsipurski, S.J.; Hettich, R. Fullerenes from the geological environment. Nature 1992, 247, 215-217.

91. Daly, T.K. A Search for Natural Fullerenes Using Mass Spectrometry; Arizona State University, MS Thesis, 1996.

92. Knell, J.E. A Search for Fullerenes in Naturally Occurring Materials; Arizona State University, 1999; MS Thesis.

93. Kholodkevich, S.V.; Bekrenev, A.V.; Domroshchenkov, V.I.; Kon'kov, O.I.; Poborchii, V.V.; Terukov, E.I.; Trapeznikova, I.N. Natural fullerenes separation from the shungite rocks of Karelia. Dokl. Akad. Nauk. 1993a, 330, 340-341.

94. Kholodkevich, S.V.; Bekrenev, A.V.; Donchenko, V.K.; Domroshchenkov, V.I.; Kon'kov, O.I.; Poborchii, V.V.; Terukov, E.I.; Trapeznikova, I.N. Isolation of natural fullerenes from Karelian shungites. Dokl. Chem. Tech. 1993b, 238/230, 22-23. 
95. Kon'kov, O.I.; Terukov, E.I.; Pfaunder, N. Fullerenes in shungite. Phys. Solid State 1994, 36, 1685-1686.

96. Masterov, V.F.; Chudnovski, F.A.; Kozyrev, S.V.; Zaidenberg, A.Z.; Rozhkova, N.N.; Podosenova, N.G.; Stefanovich, G.B. Microwave absorption in fullerene-containing shungites. Mol. Mat. 1994, 4, 213-216.

97. Zaidenberg, A.Z.; Kovalevski, V.V.; Rozhkova, N.N. Spheroidal fullerene-like carbon in shungite rock. Proc. Fullerenes Symposium; Reno: NV, 1995; 5 pp.

98. Zaidenberg, A.Z.; Kovalevski, V.V.; Rozhdova, N.N.; Tupolev, A.G. Fullerene-like structures in shungite carbon. Zh. Fiz. Khim. 1996a, 70, 107-110.

99. Zaidenberg, A.Z.; Rozhdova, N.N.; Kovalevski, V.V.; Lorents, D.C.; Chevallier, J. Physical chemical model of fullerene-like shungite carbon. Mol. Cryst. Liq. Cryst. 1996b, C8, 107-110.

100. Davydov, Y.V.; Kon'kov, O.I.; Terukov, E.I. On the existence of fullerenes in shungite rock. International Symposium on Carbonaceous Formations and Geologic History, Petrozavodsk, Russia, 1998; 42 pp.

101. Parthasarathy, G.; Srinivasan, R.; Vairamani, M.; Ravikumar, K.; Kunwar, A.C. Occurrence of natural fullerenes in low grade metamorphosed proterozoic shungite from Karelia, Russia. Geochim. Cosmochim. Acta 1998, 62, 3541-3544.

102. Gu, Y.; Wilson, M.A.; Fisher, K.J.; Dance, I.G.; Willett, G.D.; Ren, D.; Volkova, I.B. Fullerenes and shungite. Carbon 1995, 33, 862-863.

103. Heymann, D. Search for ancient fullerenes in anthraxolite, shungite, and thucholite. Carbon 1995c, 33, 237-239.

104. Ebbesen, T.W.; Hiura, H.; Hennenquist, J.W.; Deronde, C.E.J.; Andersen, A.; Ofte, M.; Melezhik, V.A. Origins of fullerenes in rocks. Science 1995, 268, 1634-1645.

105. Buseck, P.R.; Tsipurski, S.J.; Hettich, R. Origins of fullerenes in rocks. Reply to Comment. Science 1995, 268, 1634-1635.

106. Buseck, P.R.; Galdobina, L.P.; Kovalevski, V.V.; Rozhkova, N.N.; Valley, J.W.; Zaidenberg, A.Z. Shungites: the C-rich rocks of Karelia, Russia. Can. Mineral. 1997, 35, 1363-1378.

107. Amato, I. A first sighting of buckyballs in the wild. Science, 1992, 257, 167.

108. Kovalevski, V.V.; Buseck, P.R.; Cowley, J.M. Comparison of carbon in shungite rocks to other natural carbons: An X-ray and TEM study. Carbon 2001, 39, 243-256.

109. Jehlička, J.; Rouzaud, J.N. Glass-like carbon-new type of natural carbonaceous matter from Precambrian rocks. Carbon 1992, 30, $1133-1134$. 
110. Reznikov, V.A.; Polekhovskii, Y.S. Amorphous shungite carbon: a natural medium for the formation of fullerenes. Tech. Phys. Lett. 2000, 26, 689-693.

111. Oberlin, A. High-resolution TEM studies of carbonization and graphitization. In Chemistry and Physics of Carbon; Thrower, P.A., Ed.; Marcel Dekker: New York, 1989; Vol. 22, 1-144.

112. Oberlin, A. Pyrocarbons. Carbon 2002, 40, 7-24.

113. Berezkin, V.I. Genesis of Karelian shungite with reference to its distinctive structural features. Geochem. Intern. 2001, 39, 220-227.

114. Zaidenberg, A.Z.; Rozhkova, N.N.; Kovalevski, V.V.; Tupolev, A.G. Shungite carbon and fullerenes. Fullerene Sci. Techn. 1998, 6, 511-517.

115. Gómez-Lor, B.; de Frutos, Ó.; Echavarren, A.M. Synthesis of 'crushed fullerene' $\mathrm{C}_{60} \mathrm{H}_{30}$. Chem. Commun. 1999, 2431-2432.

116. Heymann, D.; Jenneskens, L.W.; Jehlička, J.; Koper, C.; Vlietstra, E.J. Biogenic Fullerenes?. Int. J. Astrobiology 2003, in press.

117. Becker, L.; Bada, J.L.; Winans, R.E.; Bunch, T.E.; French, B.M. Fullerenes in the 1.85-billion-year-old Sudbury impact structure. Science 1994b, 265, 642-645.

118. Krogh, T.E.; Davis, D.W.; Corfu, F. Precision U-Pb zircon and baddeleyite ages for the Sudbury area. In The Geology and Ore Deposits of the Sudbury Structure; Pye, E.G., Naldrett, A.J., Giblin, P.E., Eds.; Ontario Geologic Survey, 1984; Vol. 1, 431-446.

119. Corfu, F; Lightfoot, P.C. U-Pb geochronology of the sublayer environment, Sudbury igneous complex, Ontario. Economic Geol. 1996, 91, 1263-1269.

120. Peredery, W.V.; Morrison, G.G. Discussion of the origin of the Sudbury structure. In The Geology and Ore Deposits of the Sudbury Structure; Pye, E.G., Naldrett, A.J., Giblin, P.E. Eds.; Ontario Geologic Survey, 1984; Vol. 1, 491-511.

121. Dressler, B.O.; Morrison, G.G.; Peredery, W.V.; Rao, B.V. The Sudbury structure, Ontario, Canada-a review. In Research in Terrestrial Impact Structures; Pohl, J., Ed.; Viehweg \& Sohn: Braunschweig, Germany, 1987; 39-68.

122. Grieve, R.A.F.; Stoeffler, D.; Deutsch, A. The Sudbury structure: controversial or misunderstood? J. Geophys. Res. 1991, 96, 2275322764.

123. Muir, T.L.; Peredery, W.V. The Onaping formation. In The Geology and Ore Deposits of the Sudbury Structure; Pye, E.G., Naldrett, A.J., Giblin, P.E., Eds.; Ontario Geologic Survey, 1984; Vol. 1, 130-210.

124. Rousell, D.H. Onwatin and Chelmsford formations. In The Geology and Ore Deposits of the Sudbury Structure; Pye, E.G., Naldrett, A.J., Giblin, P.E., Eds.; Ontario Geologic Survey, 1984a; Vol. 1, 211-217. 
1387 125. Rousell, D.H. Mineralization in the whitewater group. In The Geology 1388 and Ore Deposits of the Sudbury Structure; Pye, E.G., Naldrett, A.J., 1389 Giblin, P.E., Eds.; Ontario Geologic Survey, 1984b; Vol. 1, 219-232.

1390 126. Becker, L.; Poreda, R.J.; Bada, J.L. Extraterrestrial helium trapped 1391 in fullerenes in the Sudbury impact structure. Science 1996, 272, 1392 249-252.

1393 127. Heymann, D.; Dressler, B.O.; Knell, J.; Thiemens, M.H.; Buseck, P.R.; 1394 Dunbar, R.B.; Mucciarone, D. Origin of carbonaceous matter, fullerenes, 1395 and elemental sulfur in rocks of the Whitewater Group, Sudbury impact 1396 structure, Ontario, Canada. In Large Meteorite Impacts and Planetary 1397 Evolution II; Dressler, B.O., Sharption, V.L., Eds.; Special Paper 339; 1398 Geological Society of America, 1999; 345-360.

1399 128. Stevenson, J.S. The Onaping ash-flow sheet, Sudbury, Ontario. In New 1400 Developments of Sudbury Geology; Guy-Bray, Ed.; Special Paper $1401 \quad$ Number 10; Geological Association of Canada, 1972; 41-48.

1402 129. Avermann, M.E. Investigations on the green member of the Onaping 1403 formation, Sudbury structure, Ontario, Canada. In Large Meteorite 1404 Impacts and Planetary Evolution; Dressler, B.O., Sharpton, V.L., Eds.; 1405 The Lunar and Planetary Institute: Houston, Texas, USA, LPI Contribu1406 tion No. 922; 1997; 4-5.

1407 130. Stöffler, D.; Deutsch, A.; Avermann, M.; Bischoff, L.; Brockmeyer, P.; 1408 Buhl, D.; Lakomy, R.; Möller-Mohr, V. The formation of the Sudbury 1409 structure, Canada: toward a unified impact model. In Large Meteorite $1410 \quad$ Impacts and Planetary Evolution II; Dressler, B.O.; Sharpton, V.L., Eds.; 1411 Special Paper No. 293; Geologic Society of America, 1994; 308-318.

1412 131. Heymann, D. Solubility of $\mathrm{C}_{60}$ and $\mathrm{C}_{70}$ in seven normal alcohols and 1413 their deduced solubility in water. Fullerene Sci. Technol. 1996b, 4, 1414 509-515.

1415 132. Jehlička, J.; Ozawa, M.; Slanina, Z.; Osawa, E. Fullerenes in solid 1416 bitumens from pillow lavas of Precambrian age (Mitov, Bohemian 1417 Massiv). Fullerene Sci. Techn. 2000, 8, 449-4523.

1418 133. Qiu, J.S.; Yang, Z.G.; Wang, N.L.; Zhang, F.; Tsang, S.C.; Harris, P.J.S. 1419 Preparation of fullerenes from several Chinese coals. Mol. Mater. 2000, $1420 \quad 13,377-384$.

1421 134. Fang, P.H.; Wong, R. Evidence for fullerene in a coal of Yunnan, 1422 Southwest China. Mater. Res. Innov. 1997, 1, 130-132.

1423 135. Alvarez, L.; Alvarez, W.; Asaro, F.; Michel, H.V. Extraterrestrial cause 1424 for the cretaceous/tertiary extinction. Science 1980, 208, 1095-1108.

1425 136. Cornejo Toledo, A.; Hernandez Osuna, A. Las anomalias gravimetricas 1426 en la cuenca salina del istmo, planicie costera de Tabasco, Campeche y 1427 Peninsula de Yucatan. Boletín de la Asociación Mexicana de Geólogos 1428 Petroleros 1950, 2, 435-460. 
137. Hildebrand, A.R.; Penfield, G.T.; Kring, D.A.; Pilkington, M.; Jacobsen, S.; Boynton, W.V. The Chicxulub crater: A possible cretaceous-tertiary boundary impact crater on the Yucatán Peninsula, Mexico. Geology 1991, 19, 867-871.

138. Wolbach, W.S.; Lewis, R.S.; Anders, E. Cretaceous extinctions: evidence for wildfires and search for meteoritic material. Science 1985, 230, 167-170.

139. Wolbach, W.S.; Gilmour, I.; Anders, E.; Orth, C.J.; Brooks, R.R. Global fire at the cretaceous/tertiary boundary. Nature 1988, 334, 665-669.

140. Wolbach, W.S.; Gilmour, I.; Anders, E. Major wildfires at the cretaceous/tertiary boundary. In Global Catastrophes in Earth History; An Interdisciplinary Conference on Impacts, Volcanism, and Mass Mortality; Special Paper 247; Sharpton, V.L., Ward, P.D., Eds.; Geological Society of America, 1990; 391-400.

141. Anders, E.; Wolbach, W.S.; Lewis, R.S. Cretaceous extinctions and wildfires. Science 1986, 234, 261-264.

142. Anders, E.; Wolbach, W.S.; Gilmour, I. Major wildfires at the cretaceous/tertiary boundary In Global Biomass Burning; Levine, J.S., Ed.; The MIT Press: Cambridge, Mass., 1991; 485-492.

143. Gilmour, I.; Wolbach, W.S.; Anders, E. Major wildfires at the cretaceous/tertiary boundary. In Catastrophes and Evolution: Astronomical Foundations; Clube, S.V.M., Ed.; Cambridge University Press: Cambridge, GB, 1990; 195-213.

144. Howard, J.B.; Mckinnon, J.T.; Makarovsky, Y.; Lafleur, A.L.; Johnson, M.E. Fullerenes $\mathrm{C}_{60}$ and $\mathrm{C}_{70}$ in flames. Nature 1991, 352, 139-141.

145. Howard, J.B. Fullerenes formation in flames. Twenty-Fourth Symposium (International) on Combustion, The Combustion Institute, 1992; 933-946.

146. Pope, C.J.; Marr, J.A.; Howard, J.B. Chemistry of fullerenes $\mathrm{C}_{60}$ and $\mathrm{C}_{70}$ formation in flames. J. Phys. Chem. 1993, 97, 11001-11013.

147. Heymann, D.; Wolbach, W.S.; Chibante, L.P.F.; Smalley, R.E. Search for extractable fullerenes in clays from the KT boundary of the Woodside Creek and Flaxbourne river sites, New Zealand. In New Developments Regarding the KT Event and Other Catastrophes in Earth History; LPI Contribution 825; Lunar and Planetary Institute: Houston, 1994a; 47-48.

148. Heymann, D.; Chibante, L.P.F.; Brooks, R.R.; Wolbach, W.S.; Smalley, R.E. Fullerenes in the K/T boundary layer. Science 1994b, 265, 645-647.

149. Heymann, D.; Wolbach, W.S.; Chibante, L.P.F.; Brooks, R.R.; Smalley, R.E. Search for extractable fullerenes in clays from the cretaceous/ tertiary boundary of the Woodside Creek and Flaxbourne River sites, New Zealand. Geochim. Cosmochim. Acta 1994c, 58, 3531-3534. 
1471 150. Heymann, D.; Chibante, L.P.F.; Smalley, R.E. Determination of $\mathrm{C}_{60}$ and $1472 \quad \mathrm{C}_{70}$ fullerenes in geologic materials by high performance liquid chro1473 matography. J. Chrom. A 1995a, 689, 157-163.

1474 151. Heymann, D.; Nazarov, M.A.; Korochantsev, A.; Smit, J. The Chicxulub 1475 event: did it produce a global layer of fullerene-bearing sediments?

1476 Lunar and Planetary Science XXVI; The Lunar and Planetary Institute:

1477 Houston, Texas, USA, 1995b; 597-598.

1478 152. Heymann, D.; Korochantsev, A.; Nazarov, M.A.; Smit, J. Search for 1479 fullerenes $\mathrm{C}_{60}$ and $\mathrm{C}_{70}$ in cretaceous-tertiary boundary sediments from 1480 Turkmenistan, Kazakhstan, Georgia, Austria, and Denmark. Cretaceous 1481 Geology 1996b, 17, 367-380.

1482 153. Heymann, D.; Yancey, T.E.; Wolbach, W.S.; Johnson, E.A.; Roach, D.; 1483 Moecker, S. Carbon in sediments at the KT boundary site of the Brazos 1484 River, Texas. Lunar and Planetary Science XXVIII; Lunar and Planetary 1485 Institute: Houston, Texas, USA, 1997; 567-568.

1486 154. Heymann, D.; Yancey, T.E.; Wolbach, W.S.; Thiemens, M.H.; 1487 Johnson, E.A.; Roach, D.; Moecker, S. Geochemical markers of the 1488 cretaceous-tertiary boundary event at Brazos river, Texas, USA. Geo1489 chim. Cosmochim. Acta 1998, 62, 173-181.

1490 155. Becker, L.; Bada, J.L. Fullerenes in the K/T boundary: are they a result 1491 of global wildfires?. Lunar and Planetary Science XXVI; Lunar and 1492 Planetary Institute: Houston, TX, USA, 1995; 85-86.

1493 156. Taylor, R.; Abdul-Sada, A.K. There are no fullerenes in the K-T 1494 boundary layer. Fullerene Sci. Techn. 2000, 8, 47-54.

1495 157. Chijiwa, T.; Arai, T.; Sugai, T.; Shinohara, H.; Kumazawa, M.; 1496 Takano, M.; Kawakami, S. Fullerenes found in the Permo-Triassic 1497 mass extinction period. Geophys. Res. Lett. 1999, 26, 767-770.

1498 158. Becker, L.; Poreda, R.J.; Hunt, A.G.; Bunch, T.E.; Rampino, M. 1499 Impact event at the Permian-Triassic boundary: evidence from 1500 extraterrestrial noble gases in fullerenes. Science 2001, 291, 1530$1501 \quad 1533$.

1502 159. Braun, T.; Osawa, E.; Detre, C.; Toth, I. On some analytical aspects of 1503 the determination of fullerenes in samples from the Permian/Triassic 1504 boundary layers. Chem. Phys. Lett. 2001, 348, 361-362.

1505 160. Farley, K.A.; Mukhopdhyay, S. An extraterrestrial impact at the 1506 Permian-Triassic boundary?. Science 2001, 293, 2343.

1507 161. Isozaki, Y. An extraterrestrial impact at the Permian-Triassic boundary?. $1508 \quad$ Science 2001, 293, 2343.

1509 162. Becker, L.; Poreda, R.J. An extraterrestrial impact at the Permian1510 Triassic boundary? A reply Science 2001, 293, 2343.

1511 163. Daly, T.K.; Buseck, P.R.; Williams, P.; Lewis, C.F. Fullerenes from a 1512 fulgurite. Science 1993, 259, 1599-1601. 
164. Osawa, E.; Hirose, Y.; Kimura, A.; Shibuya, M.; Gu, Z.; Li, F.M. Fullerenes in Chinese ink. A correction. Fullerene Sci. Techn. 1997a, 5, 177-194.

165. Osawa, E.; Hirose, Y.; Kimura, A.; Shibuya, M.; Kato, M.; Takezawa, H. Seminatural occurrence of fullerenes. Fullerene Sci. Techn. 1997b, 5, 1045-1055.

166. Wang, Z.X.; Li, X.P.; Wang, W.M.; Xu, X.J.; Zi, C.Y.; Huang, R.B.; Zheng, L.S. Fullerenes in the fossil of dinosaur egg. Fullerene Sci. Technol. 1998, 6, 715-720.

167. Heymann, D. Search for $\mathrm{C}_{60}$ fullerene in char produced on a Norway spruce by lightning. Fullerene Sci. Techn. 1998, 6, 1079-1086.

168. Fetzer, J.C. Large $(C>24)$ Polycyclic Aromatic Hydrocarbons; Wiley Interscience: New York, 2000; 288 pp.

169. Yoshimura, K.; Przybilla, L.; Ito, S.; Brand, J.D.; Wehmeir, M.; Räder, H.J.; Müllen, K. Characterization of large synthetic polycyclic aromatic hydrocarbons by MALDI- and LD-TOF mass spectrometry. Macromol. Chem. Phys. 2001, 202, 215-222.

170. Rose, H.R.; Dance, I.G.; Fisher, K. J.; Smith, D.R.; Willett, G.D.; Wilson, M.A. Calcium inside $\mathrm{C}_{60}$ and $\mathrm{C}_{70}$ from coorongite, a precursor of torbanite. J. Chem. Soc., Chem. Commun. 1993, 941942.

171. Rose, H.R.; Dance, I.G.; Fisher, K.J.; Smith, D.R.; Willett, G.D.; Wilson, M.A. From green algae to calcium inside buckyballs. Org. Mass Spectrom. 1994, 29, 470-474.

172. Fisher, K.; Largeau, C.; Derenne, S. Can oil shales be used to produce fullerenes?. Org. Geochem. 1996, 24, 715-723.

173. Crowley, C.; Taylor, R.; Kroto, H.W.; Walton, D.R.M.; Cheng, P.C.; Scott, L.T. Pyrolytic production of fullerenes. Synth. Metals 1996, 77, 17-22.

174. Sarobe, M.; Kwint, H.C.; Fleer, T.; Havenith, R.W.A.; Jenneskens, L.W.; Vlietstra, E.J.; van Lenthe, J.H.; Wesseling, M. Flash vacuum thermolysis of acenaphtol[1,2-a]acenaphtylene, fluoranthene, benzo[k]- and benzo[j]fluoranthene-homolytic scission of carbon-carbon single bonds of internally fused cyclopenta moieties at $T>=1100$ degrees C. European J. Org. Chem. 1999b, 1191-1200.

175. Mukhopadhyay, K.; Krishna, K.M.; Sharon, M. Fullerenes from camphor: a natural source. Phys. Rev. Lett. 1994, 72, 3182-3185.

176. Avermann, M.E. Origin of the polymict, allochtonous breccias of the Onaping formation, Sudbury structure, Ontario, Canada. In Large Meteorite Impacts and Planetary Evolution; Dressler, B.O., Grieve, R.A.F., Sharpton, V.L., Eds.; Geological Society of America Special Paper 293; 1994; 264-267. 
1555 177. Melezhik, V.A.; Fallick, A.E.; Filippov, M.M.; Larsen, O. Karelian 1556 shungite - an indication of 2.0-Ga-old metamorphosed oil-shale and 1557 generation of petroleum: geology, lithology and geochemistry. Earth 1558 Sci. Rev. 1999, 47, 1-40.

1559 178. Pouba, Z.; Kribek, B. Organic matter and the concentration of metals in 1560 Precambrian stratiform deposits of the Bohemian massif. Precambrian 1561 Res. 1986, 33, 225-237.

1562 179. Kannenberg, E.L.; Poralla, K. Hopanoid biosynthesis and function in 1563 bacteria. Naturwissenschaften 1999, 86, 168-176.

1564 180. Simoneit, B.R.T. Petroleum generation, an easy and widespread process 1565 in hydrothermal systems; an overview. Applied Geochem. 1990, 5, 3-15.

1566 181. Miller, J.D.A. Fats and steroids. In Physiology and Biochemistry of 1567 Algae; Levin, R.A., Ed.; Academic Press: New York, 1962; 357-370.

1568 182. Osawa, E. Natural fullerenes-Will they offer a hint to the selective 1569 synthesis of fullerenes?. Fullerene Sci. Technol. 1999, 7, 637-652.

1570 183. Standard Reference Materials Program: SRM Catalog Table 109.2.

1571 National Institute of Standards and Technology, Gaithersburg, MD, 1572 USA.

1573

1574

Received April 19, 2003

1576 Revised May 3, 2003

1577 Accepted June 2, 2003

1578

1579

1580

1581

1582

1583

1584

1585

1586

1587

1588

1589

1590

1591

1592

1593

1594

1595

1596 